\title{
Concept of Template Synthesis of Proteoglycans
}

\author{
Aleksandr N. Zimnitskii
}

Additional information is available at the end of the chapter

http://dx.doi.org/10.5772/48085

\section{Introduction}

It is accepted in modern genomics that only a minor portion (1-5\%) of the genome contains information about the primary structure of protein molecules. The higher is the organism on the evolutionary ladder, the lower the density of genetic information, in the modern sense of the term, per kilobase $(\mathrm{kb})$. For instance (Table 1), this parameter is $1-1.7 \mathrm{~kb}$ per gene in bacteria and more than $30 \mathrm{~kb}$ per gene in human.

\begin{tabular}{|c|c|c|c|}
\hline Organism & $\begin{array}{c}\text { Genome size, } \\
\mathrm{Mb}\end{array}$ & $\begin{array}{c}\text { Total genes, } \\
10^{3}\end{array}$ & $\begin{array}{c}\text { Density, } \\
\mathrm{kb} / \text { gene }\end{array}$ \\
\hline Bacteria & $0.5-5$ & $0.47-4.29$ & $1-1.7$ \\
Yeasts & 12 & 6 & 2 \\
Nematode & 97 & 19 & 5 \\
Human & 3000 & $80-100$ & $>30$ \\
\hline
\end{tabular}

Table 1. Comparison of the genome size and gene number (Kiselev, L.L., 2000)

The genome can be conventionally divided into three groups of nucleotide sequences: unique sequences, moderate repeats (DNA segments repeated frequently), and fast repeats (satellite DNA). This division is exclusively conventional; the assignment to a particular group is determined by the capability of fragmented and denatured DNA to find complementary regions upon reassociation in solution. Yet such a division makes it possible to study the functional role of individual genome regions. It was shown, for instance, that unique DNA sequences are responsible mostly for encoding the primary structure of protein molecules. Such sequences occur in a few copies in the genome. Part of information of repetitive DNA systems (histone, rRNA, and tRNA genes) is encoded by so-called slow DNA repeats

The role of fast repeats and satellite DNA is still enigmatic to a great extent. Such DNA is often called selfish or waste, suggesting a lack of information valuable for the organism. 
Surprisingly, it is this DNA that increases in amount in organisms with the highest level of organization (for instance, repetitive sequences account for more than $95 \%$ of the human genome). Data accumulating in recent decades for inverted repeats, regulatory gene regions, centromeric and telomeric satellite DNAs, introns, and mobile genetic systems still fail to improve the understanding of the functional role of tandem repeats, which quantitatively constitute the basis of the genome. The hypothesis that repeats are just dilutors of genetic information is below the level of current knowledge, testifying to a poor understanding of the phenomenon rather than helping to elucidate their role (Singer M., Berg P. 1998).

Some authors believe that tandem repeats play an important, though still unknown, part in evolutionary improvement of organisms. Thus repeats show species specificity (Mednikov B.M., et al., 2001) and occur in hundred of thousands or even millions of copies in the genome (Table 2). Simple tandem repeats, such as 5-CA, 5-GA, 5-AT, and 5-GC, are present in virtually all eukaryotes and have huge copy numbers.

\begin{tabular}{|c|c|c|}
\hline Repeat & Organisms & Purine:pyrimidine ratio \\
\hline 5-GGAAG & birds & $2: 0$ \\
\hline 5-CA & many eukaryotes & $1: 1$ \\
\hline 5-GA & many eukaryotes & $1: 1$ \\
\hline 5-GT & many eukaryotes & $1: 1$ \\
\hline 5-AT & many eukaryotes & $1: 0.9$ \\
\hline 5-CAAA & Xenopus laevis & \\
GTTTT & & $0: 2$ \\
\hline GTTTGA & & birds \\
\hline 5-TCTCC & & \\
\hline
\end{tabular}

Table 2. Some tandem repeats dispersed through the genomes of various eukaryotes (Singer, M., Berg, P., 1998)

In terms of base groups, the sequences shown in Table 2 can be presented as multiple repeats of (Pyr-Pyr), (Pur-Pur), and (Pur-Pyr), where Pyr is a pyrimidine (T or C) and Pur is a purine (A or G). Thus, the genome contains extended monopurine and/or monopyrimidine arrays as well as tandem repeats whose averaged unit contains Pur and Pyr bases in nearly equal proportions. It is also beyond doubt that excess information is read from DNA during transcription yielding gnRNA, part of which is excised during RNA maturation. Information is transferred from DNA to mRNA almost directly, without processing, in prokaryotes, whereas the situation observed in higher organisms is similar to that with DNA repeats. The higher the position of an organism on the evolutionary ladder, the greater the amount of information that is transmitted to RNA and is senseless in terms of the polypeptide sequence (Singer M., Berg P., 1998).

While DNA determines the ontogenetic and phylogenetic development of organisms and is structurally described as a polymer of dimeric units, a natural question is whether the cell possesses another structurally similar biopolymer (apart from RNA). As is well known, 
proteins are unfit for this role, because the triplet code of polypeptides requires at least three different monomers for their implementation. There is only one group of tandem biopolymers playing a key role in the functioning of higher organisms as multicellular entities. This group is polysaccharides.

Polysaccharides are biopolymers that consist of monosaccharides linked to each other. It was believed until the 1960s (Colman Y., Rem C.-G. 2000), that carbohydrates serve only as an energy source (monosaccharides and storage polysaccharides such as starch and glycogen) and structural material (e.g., cellulose in plants and chitin in insects). Interest in carbohydrates was moderated by their extreme structural complexity. While there is only one way of linking together monomers of nucleic acids (nucleotides) or proteins (amino acids), monosaccharide units of oligosaccharides and polysaccharides can be linked in several ways at several different positions. Thus only 256 tetranucleotides can be obtained with four different nucleotides, whereas four different monosaccharides can form 35,560 unique tetrasaccharides (Colman Y., Rem C.-G. 2000). Consequently, biological polymorphism of polysaccharides is immeasurably higher than that of proteins or nucleic acids (NA).

By composition, polysaccharides are usually divided into homopolysaccharides (homoglycans) and heteropolysaccharides (heteroglycans). In almost all cases, the chemical structure can be reduced to a dimeric unit repeated many times (Fig. 1, Table 3). Glycosaminoglycans (GAG) are the most common natural heteroglycans.



amylose

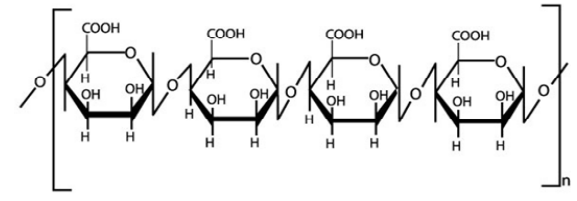

polyuronides

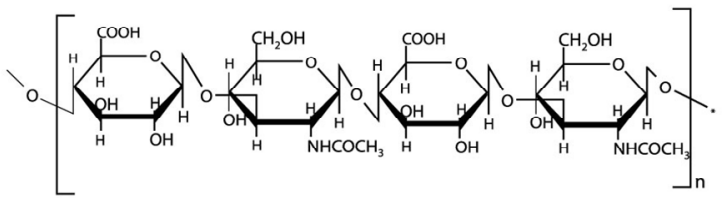

hyaluronic acid

Figure 1. Structures of common polysaccharides.

GAG is a polymer that consists of hexuronic acid and hexosamine residues linked by Oglycoside bonds. The three major GAG classes are nonsulfated hyaluronic acid (HA), moderately sulfated chondroitin sulfates (CS), and highly sulfated heparan sulfates (HS). GAG of the last two classes belong to proteoglycans. GAG contained in proteoglycans play various vital parts in the intercellular matrix and within the cell (Zimnitskii A.N., Bashkatov S.A. 2004). 


\begin{tabular}{|c|c|c|}
\hline PS, source & PS formula & Uronic acid:hexose ratio \\
\hline $\begin{array}{l}\text { Polysaccharides of } \\
\text { microorganisms }\end{array}$ & GlcUA - Glc & $1: 1$ \\
\hline $\begin{array}{l}\text { Polyuronides of } \\
\text { plants }\end{array}$ & GlcUA - GlcUA & $2: 0$ \\
\hline $\begin{array}{l}\text { Amylose and } \\
\text { cellulose of plants, } \\
\text { glycogen of animals }\end{array}$ & Glc-Glc & $0: 2$ \\
\hline $\begin{array}{l}\text { Chitin of insects } \\
\text { and crustaceans }\end{array}$ & GlcNAc-GlcNAc & $0: 2$ \\
\hline Heparan of animals & GlcUA - GlcN & $1: 1$ \\
\hline $\begin{array}{l}\text { Hyaluronic acid of } \\
\text { animals }\end{array}$ & GlcUA - GlcNAc & $1: 1$ \\
\hline $\begin{array}{l}\text { Dermatan sulfate of } \\
\text { animals }\end{array}$ & IdoUA - GalNAc & $1: 1$ \\
\hline $\begin{array}{l}\text { Chondroitin sulfate } \\
\text { (CS) of animals }\end{array}$ & GlcUA - GalNAc & $1: 1$ \\
\hline CS A of animals & GlcUA - GalNAc4SO 4 & $1: 1$ \\
\hline CS C of animals & GlcUA - GalNAc6SO 4 & $1: 1$ \\
\hline CS of animals & GlcUA3S - GalNAc4SO 4 & $1: 1$ \\
\hline CS of animals & GlcUA2S - GalNAc6S & $1: 1$ \\
\hline CS of animals & GlcUA - GalNAc(4,6-diSO4) & $1: 1$ \\
\hline CS of animals & IdoUA - GalNAc $4 \mathrm{SO}_{4}$ & $1: 1$ \\
\hline CS of animals & IdoUA2(3)SO 4 - GalNAc & $1: 1$ \\
\hline CS of animals & $\mathrm{IdoUA2}_{2}(3) \mathrm{SO}_{4}-\mathrm{GalNAc}_{4} \mathrm{SO}_{4}$ & $1: 1$ \\
\hline CS of animals & $\mathrm{IdoUA}_{2} \mathrm{SO}_{4}-\mathrm{GalNAc} \mathrm{SOO}_{4}$ & $1: 1$ \\
\hline CS of animals & IdoUA - GalNAc(4,6-diSO 4 ) & $1: 1$ \\
\hline CS of animals & $\begin{array}{l}\text { IdoUA2(3)SO } 4 \text { - GalNAc(4,6- } \\
\left.\text { diSO}_{4}\right)\end{array}$ & $1: 1$ \\
\hline $\begin{array}{l}\text { Heparan sulfate } \\
\text { (HS) of animals }\end{array}$ & IdoUA - GlcNSO 4 & $1: 1$ \\
\hline HS of animals & IdoUA - GlcNSO $46 \mathrm{SO}_{4}$ & $1: 1$ \\
\hline HS of animals & $\mathrm{IdoUA2}(3) \mathrm{SO}_{4}-\mathrm{GlcNSO}_{4}$ & $1: 1$ \\
\hline HS of animals & IdoUA2(3) - bGlcNSO $46 \mathrm{SO}_{4}$ & $1: 1$ \\
\hline HS of animals & GlcUA - GlcNSO 4 & $1: 1$ \\
\hline HS of animals & GlcUA - GlcNAc6SO 4 & $1: 1$ \\
\hline HS of animals & GlcUA - GlcNS6SO 4 & $1: 1$ \\
\hline HS of animals & $\mathrm{GlcUA}_{2} \mathrm{SO}_{4}-\mathrm{GlcNSO}_{4} 6 \mathrm{SO}_{4}$ & $1: 1$ \\
\hline HS of animals & $\mathrm{GlcUA}_{2} \mathrm{SO}_{4}-\mathrm{GlcNSO}_{4}$ & $1: 1$ \\
\hline HS of animals & $\mathrm{GlcUA}_{2} \mathrm{SO}_{4}-\mathrm{GlcNSO}_{4} \mathrm{SO}_{4}$ & $1: 1$ \\
\hline
\end{tabular}

Table 3. Uronic acid/hexose ratio in storage and structural polysaccharides (PS) 
HA biosynthesis was studied in group A hemolytic streptococci (Dorfman A 1958, 1964,1965). Similar synthetic processes occur in higher animals (Glaser L., Brown D.H. 1955). Roseman (Roseman S., Ludowieg J., et. al. 1953, Roseman S., Moses F.E., et. al. 1953, Roseman S., Moses F.E, et. al. 1954 ) have shown that D-glucose is a precursor of glycosamine and glucuronic acid, which are HA monomers. The immediate precursors of HA are uridine diphosphate (UDP) derivatives of glucuronic acid and $\mathrm{N}$-acetylglucosamine, which act as donors of carbohydrate residues during HA synthesis (Cifonelli J.A., et al. 1957, Markovic O., et al. 1964, Markovitz A., et al. 1958, Lorenzel I. 1959). A cell-free system allowing HA synthesis in the presence of UDP-glucuronic acid, UDP-glucosamine, and $\mathrm{Mg}^{2+}$ was obtained by sonicating a microbial culture producing HA (Markovic O., Huttl S. 1964). The enzyme responsible for HA synthesis sedimented at $100.000 \mathrm{~g}$. A similar enzyme was found in rat embryo skin by Schiler (Schiller S. 1964, Schiler S. 1965) and in various chicken, rodent, and human tissues by Altschuler (Altschuler C.H., et al. 1963). As in microorganisms, nucleotide derivatives result from the reactions catalyzed by pyrophosphorylases in higher animal tissues producing HA (Strominger J.L. 1964). Acetylation of UDP-glucose involves acetyl coenzyme A. Glucose is transformed into glucosamine before being linked to UDP.

As Slutskii (Slutskii L.I. 1969). showed in the late 1970s, when biosynthesis of heteroglycans of the intracellular matrix were studied most intensely in higher animals, and modern data demonstrate, the enzyme involved in synthesis of polysaccharide fragments of GAG is associated with membrane structures in the intact cell. One is forced to accept the fact that little is still understood about the mechanism of final steps of GAG biosynthesis: how it is possible that a strict alternation of acetylglucosamine and glucuronic acid residues in the macromolecular glycan chain is achieved in the absence of a template.

Studies showed that synthesis of sulfated GAG is essentially similar to synthesis of nonsulfated HA and that D-glucose is a precursor of monosaccharide residues as in the case of HA. However, a necessary step is epimerization of glucosamine into galactosamine in the case of CS and glucuronic acid into iduronic acid in the case of dermatan sulfate. Several works demonstrated epimerization of UDP-monosaccharides in the presence of $\mathrm{NADPH}^{+}$ and specific epimerases (Maley F., et al. 1959, Roden L., et al. 1958, Rondle C.J.M., et al. 1955). White (White B.N., et al. 1965) observed the reversible character of epimerization with the example of transformation of galactosamine into glucosamine during GAG synthesis. During synthesis of HS and, in particular, heparin, nucleotide derivatives of hexuronic acids and hexosamines form not only $\beta$-glycosidic bonds, characteristic of HA and CS, but also $\alpha$-glycosidic bonds, characteristic of HS (Silbert J.J. 1963).

According to current views, the first step of proteoglycan synthesis is translation of the protein core mRNA on ribosomes of the rough endoplasmic reticulum. Then glycosylation of the protein core is initiated: a site is generated at which the prospective GAG is to be linked to the polypeptide chain. This process has not been localized so far; it is known only that the protein core already has a polysaccharide fragment when delivered into the endoplasmic reticulum (Zimina N.P., et al. 1992, Zimina N.P., et al. 1987, White J, et al. 1978, Silbert J.E. et al, 1995). It is thought that synthesis of GAG chains is template-independent: 
glycosyltransferases just consecutively add monosaccharides of donor UDP-saccharides to the growing carbohydrate chain. The substrate specificity of glycosyltransferases is determined by the monosaccharide sequence. The growth of GAG chains is initiated by xylosyltransferase. However, only some serine residues of the protein core are subject to xylosylation. The site of attachment of a GAG chain is presumably selected depending on the amino acid sequence of the region to be glycosylated (Zimina N.P., et al. 1992, Zimina N.P., et al. 1987, Jeffrey D Esko, et al. 1996). After a xylose residue is linked to the protein, a carbohydrate chain is formed via adding consecutively two galactose residues and one glucuronic acid residue by galactosyltransferases I and II and glucuronyltransferase I. The newly synthesized tetrasaccharide serves as an acceptor in the first reaction of GAG synthesis. Polymeric GAG chains result from multiple reactions performed alternately by two enzymes associated with the membrane Golgi complex. These enzymes are Nacetylgalactosaminyltransferase and glucuronyltransferase II in the case of CS and dermatan sulfates. In the case of HS and heparin, polymerization is catalyzed by Nacetylglucosaminyltransferase and glucuronyltransferase (Zimina N.P., et al. 1992, Zimina N.P., et al. 1987, Sugahara K., et al. 2000, Silbert J.E. 1982). The structure of the protein core is critical for the structure of GAG chains (Jeffrey D Esko, et al. 1996).

The immediate substrates of GAG synthesis are nucleotide (UDP) derivatives of monosaccharides; these derivatives are generated in the reactions catalyzed by pyrophosphorylases. Glucuronic acid is produced from UDP-glucose via two-step oxidation of $\mathrm{C}_{6}$, with transformation of the hydroxyl group into a carboxyl group. In dermatan sulfate synthesis, UDP-glucuronic acid is epimerized into UDP-iduronic acid by specific epimerase.

Thus, during GAG biosynthesis, one enzyme complex elongates the heteroglycan chain by adding consecutively monosaccharide units. Treatment with ribonucleases or deoxyribonucleases did not prevent chain elongation in a model HA-producing system. This finding was interpreted as demonstrating the template-independent character of GAG synthesis. We think, however, that template independence of GAG synthesis is not evident from this finding, because the glycans produced in the model system were not compared with natural glycans. It is beyond doubt that, in the absence of a template, the enzyme complex is capable of producing a heteroglycan chain at random, as is the case with NA synthesis in in vitro systems.

To eliminate the contradiction between the clearly ordered GAG structure (Zimina N.P., et al. 1992, Zimina N.P., et al. 1987 ) and the concept of non-template GAG synthesis, attempts were made over the past decade to associate the ordered character of the GAG structure with template synthesis of the protein core of proteoglycans; i.e., the amino acid sequence of the protein core was considered as a kind of a template for GAG synthesis. Although some achievements were made in the field, they mostly revealed statistical, rather than cause-andeffect, relationships. It seems that this situation has been accepted as satisfactory, and the concept of non-template GAG synthesis associated with the protein core is now described in textbooks. Yet the concept is shattered completely by the fact that that HA, reaching a molecular weight of $10^{7} \mathrm{Da}$, is an individual GAG lacking any protein core, in contrast to CS and HS. 
Current views of proteoglycan biosynthesis are related to studies of the role of intracellular membranes. It is commonly known that cell proteoglycans are almost always associated with membrane structures. The processes of proteoglycan biosynthesis, intracellular transport to organelles, and transfer onto the cell surface in the intercellular matrix are coupled with the functioning of membranes. GAG accumulation in lysosomes and subsequent cleavage to monosaccharides are also connected with the functioning of membrane structures. Free proteoglycans and GAG that are not associated with membranes are detectable only at the last degradation stages in lysosomes and some other cell structures such as the nucleus and mast cell granules.

Scarce, if any, information is available concerning the early steps of GAG synthesis and GAG transport to the sites where polysaccharide chains are generated (Silbert J.E. et al. 1995). As the views of the structure of the protein core are generally discrepant, it is still unclear whether the protein core determines the formation of proteoglycans. The primary structure of a core protein with a potential serine xylosylation site suggests that the protein molecule plays no crucial role in recognition of the xylosylation site. Hence it is probable that the conformation of membrane structures is a factor determining the recognition of xylosylation sites in protein molecules of proteoglycans. This assumption can be advanced because the main determinant of xylosylation is probably associated with membrane structures of the endoplasmic reticulum and Golgi complex, where glycosyltransferase activity is high (Silbert J.E. et al. 1995).

Synthesis of the linker tetrasaccharide (an uronic acid residue is added to the trisaccharide) initiates addition of a particular $\mathrm{N}$-acetylhexosamine and thereby determines which GAG chain is to be generated. As a result, the nascent proteoglycan is transferred into the corresponding site, containing either galactose $\mathrm{N}$-acetyltransferases or glucose $\mathrm{N}$ acetyltransferases; this determines the chain to be synthesized. It is the amino acid sequence of the peptide moiety that determines the position of the nascent proteoglycan on membrane structures and, consequently, the direction of synthesis and modification of the polysaccharide chain by the corresponding enzyme systems.

The primary structure of GAG in proteoglycan molecules is an important factor determining their function. For instance, the GAG chain size, the number and location of sulfo groups, and epimerization affect the properties and biological role of proteoglycans. The extent of modification of the polysaccharide chain and its size probably depend on the structure of membrane-associated complexes responsible for proteoglycan synthesis. Membrane enzyme complexes play a key role in epimerization and/or sulfation of GAG polysaccharide chains (Silbert J.E. et al. 1995).

In 1987, Lindahl (Lindahl U., et al. 1987) showed convincingly that the results of GAG biosynthesis in vitro cannot be extrapolated to the in vivo situation. Studying heparin biosynthesis, these researchers observed that polysaccharides obtained with intact microsomes contain extended sequences of both $\mathrm{N}$-sulfated and $\mathrm{N}$-acetylated disaccharides, suggesting a nonrandom character of their synthesis. In contrast, products obtained with a solubilized microsomal system displayed a random distribution of such groups with a 
greater portion of N-acetylated and N-sulfated disaccharides (Lindahl U., et al. 1987). In fact, this finding demonstrates that synthesis of the glycoside moiety of proteoglycans is genetically determined in vivo, because their primary structure is tissue- and speciesspecific.

A basic unit monomers of polysaccharides is glucose, which occurs in solution both in the $\alpha$ and in the $\beta$ form owing to the mutarotation reaction. In addition, glucose can be epimerized to other hexoses and be oxidized to yield glucuronic and other hexuronic acids. Owing to such lability of glucose, biosynthetic systems always contain sufficient amounts of the $\alpha$ and $\beta$ forms of hexoses and hexuronic acids. Modified with UDP at $C_{1}$, these monosaccharides provide the main components for synthesis of polysaccharide chains.

As Fig. 1 and Table 3 demonstrate, the majority of known structural and storage polysaccharides each consist of two monomers, a hexose and hexuronic acid, which occur in the $\alpha$ or $\beta$ form, are linked through (1-3), (1-4) O-glycoside bonds, and are modified to a various extent at various carbon atoms as a result of acetylation, amination, sulfation, etc. All these biopolymers can be combined in one group with a universal structure of multiply repeated (A-B), (A-A), or (B-B) units, where A is a hexose and B is a hexuronic acid.

We think that the periodicity of the primary structure is similar between polysaccharides and DNA tandem repeats. In view of this structural similarity, it was justified and important to study a possible complementarity between monosaccharides of glycans and bases of NA.

To check the hypothesis of complementarity of NA bases to hexoses and hexuronic acids, quantum chemical methods were used in our lab for a particular case of glucose and glucuronic acid contained in the heteropolysaccharide HA. It is clear that such an approach is computational and that the relevant conclusions need experimental verification. In view of this, it was necessary to obtain empirical information supporting or contradicting the results of quantum chemical computations. For this purpose, we employed UV spectrophotometry and dot hybridization, which allow detection of specific complexes of biopolymers.

Since the mechanism initiating GAG biosynthesis is unclear, it was expedient to study glycan synthesis in the rat liver upon administration of elevated doses of glucose. The use of ${ }^{35} \mathrm{SO}_{4}{ }^{2-}$ as a radioactive label is inadequate for studying GAG synthesis, and we decided to label a precursor of the glycan polysaccharide chain. We used glucose as such a precursor: glucose is transformed into UDP-glucose and then into UDP-glucuronic acid, which is utilized in GAG synthesis. It should be noted that ribose 5-phosphate, which is formed from glucose 6-phosphate, is incorporated in NA. Glucose is converted into ribose in the pentose phosphate cycle by eliminating $\mathrm{C} 1$, which is released as carbon dioxide. Hence, we used $\left[{ }^{14} \mathrm{C}\right]$ glucose labeled at $\mathrm{C}_{1}$ to prevent generation of radiolabeled NA in our experiments. We studied the composition of rat liver polysaccharides in cell nuclei, microsomes, and in a total liver homogenate. In addition, the nuclear and microsomal fractions were used to monitor the accumulation of radiolabeled saccharides, which are polysaccharide precursors. 


\section{Experimental}

Quantum chemical modeling of biological structures, in particular, the geometric and electron structures of NA and polysaccharides, requires that the methods used report adequately the effects of weak intermolecular interactions, such as hydrogen bonds. The MP2 (ab initio) procedure, which utilizes bases with diffuse and polarization functions, meets this requirement quite well (Cybulski S.M., et al. 1989, Latajka Z. et al. 1990) but is hardly suitable for our objects because of their size: their analysis would be extremely timeconsuming and requiring excessive computational resources. A possible alternative in this situation is provided by the corresponding semiempirical methods. Early semiempirical methods (MINDO/3 and MNDO) considerably underestimated the energy of hydrogen bonds and, consequently, were unsuitable for studying biopolymers (Williams I.H. 1987). To eliminate such drawbacks, the AM1 (Dewar M.J.S., et al. 1985) and PM3 (Stewart J.J.P. 1989) methods were developed on the basis of neglect of diatomic differential overlap (NDDO). These methods were expected to adequately describe systems with hydrogen bonds. This was not the case with AM1: while computed energies of hydrogen bonds agreed well with experimental estimates, geometric parameters failed to represent the facts (Jurema J.M.W., et al. 1993). Parametrization was performed with a far greater body of experimental data in PM3 than in other semiempirical methods, which allowed PM3 to describe well the geometric structure of molecules and the heat of their generation. PM3 is indeed the first method yielding semiempirical estimates that agree with the results of experiments and $a b$ initio calculations for hydrogen-bonded systems (Kallies B., et al.1995).

\subsection{Method of calculation $A b$ initio}

$A b$ initio calculations are the main computational procedure in quantum chemistry and consists in solving Hartree-Fock one-electron equations. As initial data, the method utilizes the charges of nuclei, their positions in the molecule, and Slater- or Gaussian-type basis function sets. The method involves none of the observed physico-chemical properties of substances and, accordingly, is known as unempirical calculations. Ab initio calculations most commonly employ the MO LCAO (molecular orbitals as a linear combination of atomic orbitals) approximation, which takes account of all electrons of the system in question. This method is most accurate in quantum chemical computations, especially with intermediate $\left(6-31 \mathrm{G}^{*}\right)$ and large $\left(6-31^{* *}\right)$ bases, and allows correct estimation of the electron and geometric structures of hydrogen bonds, which play an important role in biological objects.

Both unempirical ab initio calculations with basis 6-31G* and the PM3 semiempirical method were employed in theoretical computations in this work. Geometric parameters and energy characteristics were computed by the unempirical and semiempirical methods for interacting nucleotides and saccharides and by the semiempirical methods for structures containing several pairs of nucleotides and saccharides. All computations were performed with complete optimization of geometrical parameters, using the GAMESS program (Schmidt M.W., et al. 1993). A global minimum of the total electron energy was sought by 
the Newton-Raphson method with an energy gradient of $0.010 \mathrm{kcal} / \mathrm{mol} \cdot \AA$, starting from various initial approximations of the complex structure.

\subsection{Isolation of oat polyuronides}

Fresh oat seedlings grown for 10-12 days were thoroughly ground and hydrolyzed with 2 $\mathrm{M} \mathrm{NaOH}(1: 10 \mathrm{w} / \mathrm{v})$ at room temperature with occasional stirring for 1 day. The hydrolysate was neutralized with concentrated $\mathrm{HCl}$ to $\mathrm{pH} 7.0$ and filtered through filter paper. Gel filtration on Sephadex G-25 was used to remove salts and low-molecular-weight components and to isolate a high-molecular-weight fraction containing polysaccharides. The preparation collected to obtain polyuronides was fractionated by anion-exchange chromatography on DEAE cellulose. The preparation was applied onto a column with fibrous DEAE cellulose (a chloride form) equilibrated with distilled water. The column was washed consecutively with distilled water and with 0.15 and $0.5 \mathrm{M} \mathrm{NaCl}$ to the minimal $\mathrm{A}_{220}$ of the eluate. Then, polyuronides were eluted with $1.5 \mathrm{M} \mathrm{NaCl}$. To remove $\mathrm{NaCl}$, the resulting fraction was subjected to gel filtration on Sephadex G-25; the presence of chlorides was checked using silver nitrate. The preparation was dried under vacuum at $45^{\circ} \mathrm{C}$ and proved to contain glucuronoxylans with a purity of no less than $95 \%$ and a proportion of hexuronic acids of no less than $95 \%$. The quality of the product was checked by the Dishe test for uronic acids. The product was dissolved to $0.1 \mathrm{mg} / \mathrm{ml}$. A $0.5-\mathrm{ml}$ aliquot of the solution was combined with $3 \mathrm{ml}$ of concentrated sulfuric acid containing $0.025 \mathrm{M}$ sodium tetraborate and thoroughly mixed. The mixture was heated in boiling water for $10 \mathrm{~min}$, chilled to room temperature, combined with $0.1 \mathrm{ml}$ of $0.1 \%$ carbazole (ethanol solution), heated in boiling water for $15 \mathrm{~min}$, and chilled. A530 was measured against a control sample. The polyuronide concentration $(\mathrm{mg} / \mathrm{ml})$ was estimated using a calibration plot, which was constructed using aqueous solutions of glucuronic acid.

\subsection{Isolation of garlic glucuronoxylans}

Unpeeled garlic bulbs were thoroughly ground and hydrolyzed with $2 \mathrm{M} \mathrm{NaOH}(1: 10 \mathrm{w} / \mathrm{v})$ at room temperature with occasional stirring for 1 day. The hydrolysate was neutralized with concentrated $\mathrm{HCl}$ to $\mathrm{pH} 7.0$ and filtered through filter paper. Gel filtration on Sephadex G-25 was used to remove salts and low-molecular-weight components and to isolate a highmolecular-weight fraction containing polysaccharides. The preparation collected to obtain glucuronoxylans was fractionated by anion-exchange chromatography on DEAE cellulose. The preparation was applied onto a column with fibrous DEAE cellulose (a chloride form) equilibrated with distilled water. The column was washed consecutively with distilled water and with 0.15 and $0.3 \mathrm{M} \mathrm{NaCl}$ to the minimal $\mathrm{A}_{220}$ of the eluate. Then, glucuronoxylans were eluted with $0.5 \mathrm{M} \mathrm{NaCl}$. To remove $\mathrm{NaCl}$, the resulting fraction was subjected to gel filtration on Sephadex G-25; the presence of chlorides was checked using silver nitrate. The preparation was dried under vacuum at $45^{\circ} \mathrm{C}$, yielding glucuronoxylans in a dry form. The quality of the product was checked by the Dishe test for uronic acids as above. The purity of the product was no less than $95 \%$; the proportion of hexuronic acids was $20 \%$. 


\subsection{Isolation of GAG (HA, CS, and HS) from human placenta}

Placenta was thoroughly ground and hydrolyzed with $2 \mathrm{M} \mathrm{NaOH}(1: 10 \mathrm{w} / \mathrm{v})$ at room temperature with occasional stirring for 3 days. The hydrolysate was neutralized with concentrated $\mathrm{HCl}$ to $\mathrm{pH}$ 7.0. To precipitate nonhydrolyzed proteins, concentrated trichloroacetic acid (TCA) was added slowly to a final concentration of $5 \%$. The preparation was incubated at $4^{\circ} \mathrm{C}$ for $1 \mathrm{~h}$, and the precipitate was removed by centrifugation at $1500 \mathrm{~g}$ for 10 min. Concentrated $\mathrm{NaOH}$ was added to the supernatant to $\mathrm{pH} 10-11$, because some proteins withstanding TCA treatment precipitated in an alkaline milieu. The precipitate was allowed to form and was removed by centrifugation $(1500 \mathrm{~g}, 10 \mathrm{~min})$. The supernatant was filtered through filter paper. Gel filtration on Sephadex G-25 was used to remove salts and low-molecular-weight components and to isolate a high-molecular-weight fraction containing GAG.

The preparations used to isolate HA and CS were fractionated by anion-exchange chromatography on DEAE cellulose. Each preparation was applied individually onto a column with fibrous DEAE cellulose (a chloride form) equilibrated with distilled water. The column was washed consecutively with distilled water and $0.15 \mathrm{M} \mathrm{NaCl}$ to the minimal $\mathrm{A}_{220}$ of the eluate. Then HA was eluted with $0.25 \mathrm{M} \mathrm{NaCl}$; CS, with $0.7 \mathrm{M} \mathrm{NaCl}$; and HS, with 1.5 $\mathrm{M} \mathrm{NaCl}$. To remove $\mathrm{NaCl}$, each fraction was subjected to gel filtration on Sephadex G-25; the presence of chlorides was checked with silver nitrate. The resulting fractions were dried under vacuum at $45^{\circ} \mathrm{C}$ to obtain $\mathrm{HA}, \mathrm{CS}$, and $\mathrm{HS}$ in a dry form. The purity was no less than $95 \%$. The quality of the products was checked by the Dishe test for uronic acids as above.

\subsection{NA and amylose}

The single-stranded probe $\mathrm{d}(\mathrm{T})_{16}$ was obtained from Sintol (Russia). Garlic DNA was isolated from root meristem tissue of seedlings. Human DNA was isolated from the placenta by phenol-detergent extraction (Belozersky A.N. 1970). The purity and concentration of DNA were checked by optical density and by Hoechst 33258 fluorescence, using a DNA minifluorimeter (Hoefer Scientific Instruments, United States). Fragmented calf thymus double-stranded DNA (MW 1 x 106 Da) and single-stranded polynucleotides $\mathrm{d}(\mathrm{A})_{350}, \mathrm{~d}(\mathrm{C})_{350}$, and $\mathrm{d}(\mathrm{GC})_{350}$ were purchased from Amersham Biosciences. Amylose was purchased from Serva Feinbiochemica GMBH.

\subsection{Spectrophotometric assays}

Working solutions of polynucleotides were prepared in a quartz cuvet with a light path of 2 $\mathrm{mm}$. Small $(5-25 \mu \mathrm{l})$ aliquots of a stock polynucleotide solution were added to $0.3 \mathrm{M} \mathrm{NaCl}$, $0.002 \mathrm{M}$ Na-phosphate ( $\mathrm{pH}$ 6.8) to the final volume $400 \mu \mathrm{l}$. After recording the absorption or circular dichroism (CD) spectra of a polynucleotide solution, polynucleotide-polysaccharide complexes were obtained. For this purpose, $400 \mu \mathrm{l}$ of the polynucleotide solution were combined in the cuvet with an aliquot of a stock polysaccharide solution with continuous stirring. Then the absorbance or CD spectra were recorded again. 
The annealing of double-stranded DNA with the corresponding polysaccharide was carried out in a closed quartz cuvet with a light path of $2 \mathrm{~mm}$. The cuvet containing DNA and the polysaccharide in certain proportions was heated in boiling water for $2 \mathrm{~min}$ and immediately chilled in ice-cold water $\left(0^{\circ} \mathrm{C}\right)$ for $30 \mathrm{~s}$. Then the absorbance or CD spectra were recorded.

The absorbance spectra were obtained using a Specord M-40 spectrophotometer. The CD spectra of complexes were recorded with an SKD-2 portable dichrometer (Institute of Spectroscopy, Russian Academy of Sciences, Troitsk). The CD spectra were presented as a wavelength dependence of the $C D$ value $\Delta A=A_{L}-A_{R}$ (Dunin V.V., et al. 1979).

\subsection{NA radiolabeling}

NA were 5'-endlabeled in vitro with $\gamma$-[32P]ATP and T4 polynucleotide kinase (Maxam A., et al. 1977). Dephosphorylation was carried out in $50 \mathrm{mM}$ Tris-HCL (pH 9.0), $10 \mathrm{mM} \mathrm{MgCl}$, $10 \mathrm{mM}$ spermidine, $1 \mathrm{mM} \mathrm{ZnCl}$, 0.1 units of alkaline phosphatase at $37^{\circ} \mathrm{C}$. The enzyme was removed by treating the samples twice with phenol. NA was precipitated with ethanol and collected by centrifugation in a minicentrifuge at 12,000 rpm for $5 \mathrm{~min}$. The pellet was washed with $70 \%$ ethanol to remove phenol, dried, and dissolved in a necessary volume of bidistilled water. The resulting solution was combined with a kinase buffer (50 $\mathrm{mM}$ Tris$\mathrm{HCl}$, pH 7.6), $10 \mathrm{mM} \mathrm{MgCl}$, $50 \mathrm{mM}$ dithiothreitol, $1 \mathrm{mM}$ spermidine), 1-2 $\mathrm{MBq}$ of $\left.\gamma-{ }^{32} \mathrm{P}\right] \mathrm{ATP}$, and 2 units of T4 polynucleotide kinase. The mixture was incubated at $37^{\circ} \mathrm{C}$ for $30 \mathrm{~min}$. The reaction was terminated by adding EDTA to $20 \mathrm{mM}$, and the enzyme was removed by phenol treatment. NA was precipitated with ethanol, and the nonbound label was removed by repeated precipitation with ethanol or by gel filtration on Sephadex G-25.

\subsection{Dot hybridization}

BA83 and BA85 filters (Schleicher \& Shuell, Germany) with immobilized DNA and polysaccharides $\left(20 \mu \mathrm{g}\right.$ per dot) were hybridized with radiolabeled NA probes at $37^{\circ} \mathrm{C}$ for $18-24 \mathrm{~h}$. The hybridization buffer contained $5 \mathrm{x}$ Denhardt's solution $(0.02 \%$ bovine serum albumin, $0.02 \%$ polyvinylpyrrolidone, $0.02 \%$ Ficoll), 0.1\% SDS (Denhardt D.T. 1966). Before being applied onto a filter, DNA was denatured in boiling water for $5 \mathrm{~min}$. Filters were dried and exposed with a PM-B X-ray film for 1-7 days.

\subsection{Neutral sugar assays}

Neutral sugars (monosaccharides contained in protein-polysaccharide complexes) were assayed by the anthrone method according to (Jermyn M.A. 1975, Chaplin M.F., et al. 1986). A sample $(0.5 \mathrm{ml})$ was combined with $4 \mathrm{ml}$ of an anthrone reagent $(20 \mathrm{mg}$ of anthrone, 100 $\mathrm{ml}$ of $80 \%$ sulfuric acid). The mixture was heated in boiling water for $5 \mathrm{~min}$, chilled in water to room temperature, and tested for A630. As a control, we used an aqueous solution water treated with the anthrone reagent as above. Neutral sugars were quantitated using a calibration plot, which was constructed with galactose solutions. 
To study the GAG composition, a homogenate and the nuclear fraction of the liver were obtained from intact adult rats after fasting over $24 \mathrm{~h}$. To estimate the contents of glycans (HA, CS, and HS), alkaline lysis, deoxyribonuclease treatment, gel filtration on Sephadex G25 , and ion-exchange chromatography on DEAE cellulose were performed as above. Polysaccharide elution profiles were obtained with a gradient of $\mathrm{NaCl}$ concentration (0-1.5 M). DNA was assayed in nuclei and liver homogenates as in (Slutskii L.I. 1969).

In the next series of experiments, non-inbred white rats weighing 190-210 g were injected intraperitoneally with $\left[{ }^{14} \mathrm{C}\right]$ glucose, labeled at $\mathrm{C} 1$, at $1 \mathrm{~g}$ per $\mathrm{kg}$ body weight $\left(4 \times 10^{8} \mathrm{~Bq}\right.$ per rat). Rats were sacrificed and the liver frozen in liquid nitrogen 15, 30, 60, 120, and $360 \mathrm{~min}$ after the injection. Differential centrifugation was used to obtain the nuclear and microsomal fractions (Orekhovich V.N. 1968), which were tested for radioactivity. Tissue homogenates were obtained similarly; their GAG fractions were isolated and tested for radioactivity.

The results were statistically processed using the software package STATISTICA 6.0 for WINDOWS. The processing included computation of the mean and standard deviation, tests for significance of differences; and correlation, regression, and factor analyses as well as analysis of variance.

\section{Results}

\subsection{Quantum chemical analysis}

\subsubsection{Analysis of the electron and geometric structures of hydrogen bonds in complementary pairs of NA by the PM3 method}

As a control, computations were performed for the interactions of bases in classical complementary pairs AT and CG, which are DNA components. Selection of computation models showed that substitution of methyl groups for the sugar-phosphate backbone has no effect on the parameters of hydrogen bonds, but considerably reduces the computation time. It was found that the PM3 method adequately describes the geometric and electron structures of hydrogen bonds in AT and CG pairs. The two interacting molecules are lying approximately in the same plane.

In the AT pair, the bases form two hydrogen bonds, one between the amino and keto groups and the other between nitrogen atoms of the purine and the pyrimidine. The mean length of the bonds is about $1.8 \AA$, and their total energy is $-5.55 \mathrm{kcal} / \mathrm{mol}$ (Fig. 2). In the CG pair, three hydrogen bonds are formed, including two between the amino and keto groups of the bases and one between nitrogen atoms. The mean length of the hydrogen bonds is also about $1.8 \AA$ A (Fig. 2), similar to that reported in (Singer M., Berg P., 1998). The total energy of the three hydrogen bonds is $-11.73 \mathrm{kcal} / \mathrm{mol}$ (Fig. 2). Thus, the PM3 method can be used to study other types of hydrogen bonds formed by nucleotide bases.

The results of computations performed by the PM3 methods for pairs of noncomplementary nucleotides are shown in Table 4. 


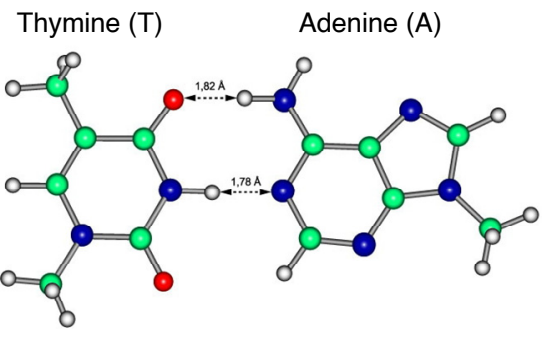

$\Delta \mathrm{E}=-5.55 \mathrm{kcal} / \mathrm{mol}$
Cytosine (C) Guanine (G)

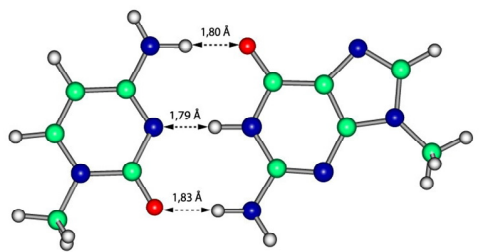

$\Delta \mathrm{E}=-11.73 \mathrm{kcal} / \mathrm{mol}$

Figure 2. Hydrogen bonding in the AT and CG pairs of complementary nucleotides. Quantum chemical analysis by the PM3 method. Here and below, carbon atoms are shown green or black; oxygen atoms, red; nitrogen atoms, blue; and hydrogen atoms, gray.

\begin{tabular}{|c|c|c|c|c|}
\hline & T & A & C & G \\
\hline T & -2.79 & & & \\
\hline A & -5.55 & -2.71 & & \\
\hline C & -4.46 & -6.07 & -9.24 & \\
\hline G & -6.12 & -7.08 & -11.73 & -10.57 \\
\hline
\end{tabular}

Note: Energy (kcal/mol) was computed by the PM3 method.

Table 4. Energy of hydrogen bonds in all possible pairs of thymine (T), adenine (A), cytosine (C), and guanine

$$
\text { A-A }
$$

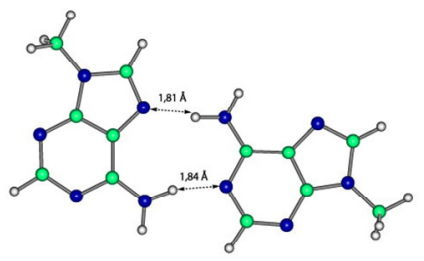

$\Delta \mathrm{E}=-2.71 \mathrm{kcal} / \mathrm{mol}$
C-A

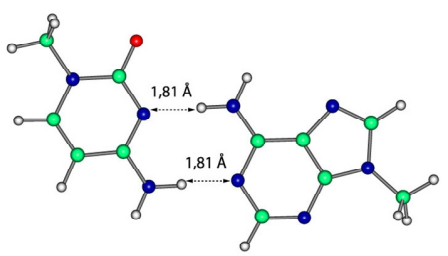

$\Delta \mathrm{E}=-6.07 \mathrm{kcal} / \mathrm{mol}$

G-A



$\Delta \mathrm{E}=-7.08 \mathrm{kcal} / \mathrm{mol}$

Figure 3. Hydrogen bonding in the noncomplementary pairs AA, GA, and CA. Quantum chemical computations by the PM3 method. 
As follows from Table 4, A is theoretically capable of forming pairs with a total energy of $2.71(\mathrm{~A}),-5.55(\mathrm{~T}),-6.07(\mathrm{C})$, and $-7.08(\mathrm{G}) \mathrm{kcal} / \mathrm{mol}$. Based on the energy, the preferential partner of $A$ is $G$ or at least $C$, but it is actually $T$. Let us consider in more detail the results of computations performed for the interactions of A with A and G with C (Fig. 3).

As Fig. 3 demonstrates, hydrogen bonding between noncomplementary nucleotides is possible, but the pairs are formed so that the angle between the interacting nucleotides is distorted in the case of AA and GA (Fig. 4) or the necessary distance between two strands in the NA double helix is not maintained in the case of CA (Fig. 4). The distance is higher in CA (Singer M., Berg P., 1998).


Figure 4. Geometric structure of hydrogen bonds in the complementary pairs AT and CG.

The above data allow the following conclusions.

1. As found by the PM3 method, complementarity in the AT and GC pairs is determined not only by the energy of hydrogen bonding.

2. Complementarity is mostly due to the orientation of hydrogen bonds formed between the interacting nucleotides and the distance between deoxyribose residues in the NA double helix.

\subsubsection{Analysis of the electron and geometric structures of hydrogen bonds in} complementary NA pairs by non-empirical ab initio calculations in the 6-31G* basis set

Calculations were performed again by the ab initio method with the $6-31 \mathrm{G}^{*}$ basis set with complete optimization of the geometric structure (Fig. 5).

$A b$ initio calculations in the $6-31 \mathrm{G}^{*}$ basis also demonstrated the formation of proper hydrogen bonds in complementary pairs. The energy estimates of the bonds were about twice higher than with the PM3 method, the lengths of the bonds were about $0.2 \AA$ greater, but their bond orders remained the same. Electron density analysis according to Mulliken 
(Mulliken R.S.,1955) showed that the charge of the hydrogen atoms is positive, about $+0.5 \mathrm{e}$, while the interacting $\mathrm{O}$ and $\mathrm{N}$ atoms have a negative charge ranging from -0.68 to $-0.83 \mathrm{e}$. As above, these results suggest quite stable hydrogen bonds.

Then, we performed $a b$ initio calculations for noncomplementary pairs of adenine with other nucleotides (Table 5).

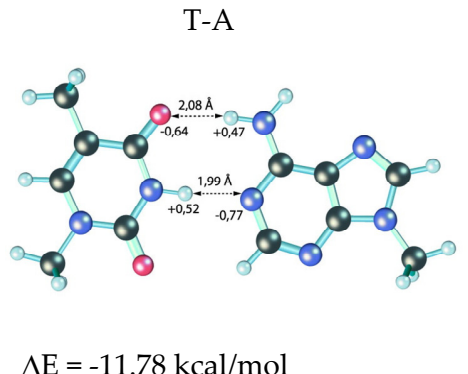

$\Delta \mathrm{E}=-11.78 \mathrm{kcal} / \mathrm{mol}$

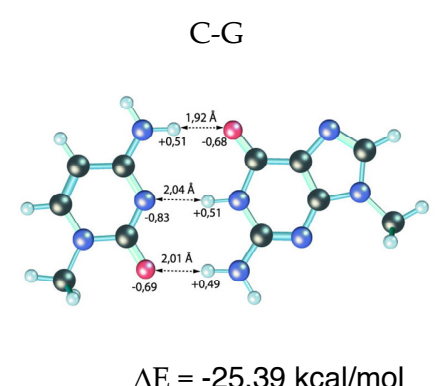

$\Delta \mathrm{E}=-25.39 \mathrm{kcal} / \mathrm{mol}$

Figure 5. Hydrogen bonding in the complementary pairs AT and CG. Quantum chemical computation by the $a b$ initio method in the $6-31 \mathrm{G}^{*}$ basis. The charges computed according to Mulliken are shown for the atoms involved in hydrogen bonding.

\begin{tabular}{|c|c|c|c|c|}
\hline Nucleotides & T & A & C & G \\
\hline A & -11.78 & -8.93 & -12.51 & -13.84 \\
\hline
\end{tabular}

Note: Energy $(\mathrm{kcal} / \mathrm{mol})$ was estimated by ab initio calculations in the $6-31 \mathrm{G}^{*}$ basis.

Table 5. Energy of hydrogen bonds in pairs of A with T, A, C, and G

As Table 5 demonstrates, selection of complementary $\mathrm{T}$ for $\mathrm{A}$ is not most advantageous in terms of energy. The interactions AC and AG are more advantageous. The selectivity of nucleotide matching is due to the specific geometric structure of the NA double helix (Fig. 4) (Singer M., Berg P. 1998). Thus, ab initio calculations in the $6-31 G^{*}$ basis confirmed that complementarity in the AT and CG pairs is determined mostly by the orientation of hydrogen bonds formed between the interacting nucleotides and the distance between deoxyribose residues in the NA double helix, rather than by the energy of hydrogen bonding.

\subsubsection{Analysis of the electron and geometric structures of hydrogen bonds in complementary pairs within the NA double helix by the PM3 method}

Let us construct a model NA double helix of six nucleotide pairs (C-G, A-T, T-A, G-C, C-G, and A-T) and fully optimize their electron structure by the PM3 method.

The results showed that a right-turn helix is produced (Fig. 6), which agrees with experimental data. The lengths of the hydrogen bonds in the DNA double helix coincide within $0.02 \AA$ with those computed for isolated nucleotides. The energy of the hydrogen bonds is $\Delta \mathrm{E}=-8.82 \mathrm{kcal} / \mathrm{mol}$ per nucleotide pair, which is approximately the average of the energies in two different nucleotide pairs $(-5.55$ and $-11.73 \mathrm{kcal} / \mathrm{mol})$. Thus, the results of 
computations make it possible to assume that only the above interactions in nucleotide pairs occur in DNA and that there are no other significant interactions.

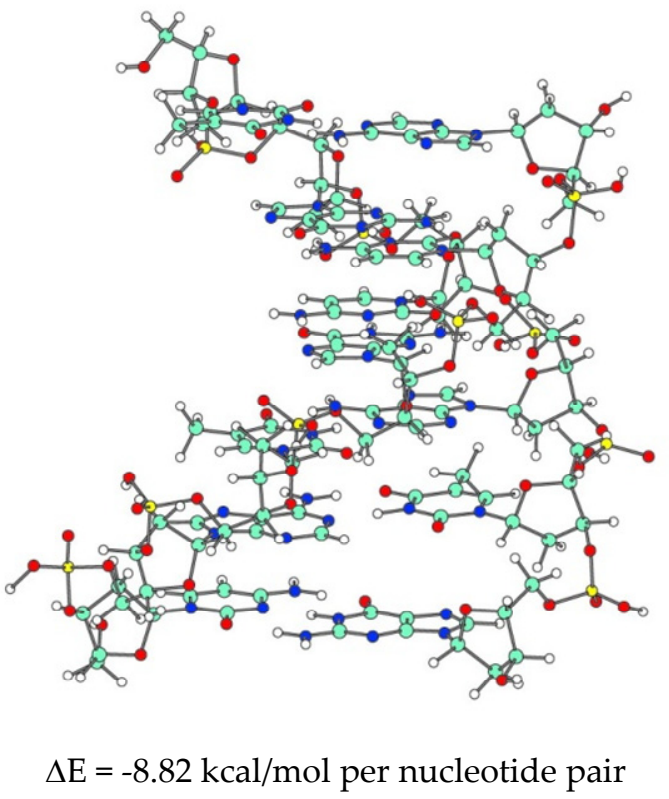

Figure 6. Hydrogen bonding in complementary pairs AT and CG contained in the DNA double helix (exemplified by a 6-bp duplex). Quantum chemical computation by the PM3 method.

Computations performed for mismatching nucleotide pairs contained in the NA double helix yielded the following picture. In the case of two pyrimidines ( $\mathrm{T}$ and $\mathrm{C}$ ), the energy of interaction is equal to zero, because the internucleotide distance is too high. In the case of two purines (A and $G$ ), there is not sufficient room for the nucleotides: their rings are bent and the sugar-phosphate backbones forced apart. This is disadvantageous in terms of energy; the loss in electron energy is about $120 \mathrm{kcal} / \mathrm{mol}$. The interactions of $\mathrm{T}$ with $\mathrm{G}$ and $\mathrm{A}$ with $\mathrm{C}$ are also disadvantageous, because the parallel arrangement of nucleotides is distorted.

Thus, the quantum chemical computations allow the following conclusions.

1. Hydrogen bonds are formed in the complementary pairs AT and GC, but nucleotide selectivity during NA synthesis is not due to the difference in energy of hydrogen bonds.

2. Selectivity is due to the geometric structure of the NA double helix, which allows the interaction for only those nucleotides that match each other by geometric parameters (AT and GC pairs). All other interactions are disadvantageous in terms of energy.

At the next step, we studied the possibility of complexation of NA bases with carboxyl or hydroxymethyl groups of polysaccharides. The questions were whether hydrogen bonds can be formed between NA bases and sugars and how the four NA bases interact with polysaccharide structural units (UDP-glucose and UDP-glucuronic acid). In addition, it was 
important to analyze how selectivity may be achieved in template synthesis of a polysaccharide (e.g., HA) on NA.

\subsubsection{Quantum chemical analysis of the electron and geometric structures of hydrogen} bonds in complementary pairs of NA and polysaccharides by the PM3 method

First, a model was selected for calculations. We found that substitution of glucuronic acid for UDP-glucuronic acid does not affect the hydrogen bonding parameters, but substantially reduces the computation time. Hence the UDP moiety attached to a sugar was omitted in further computations.

Let us assume that NA interacts with the carboxyl or hydroxymethyl group linked to C5 of a monosaccharide unit. Complete optimization of the geometric structure was performed for complexes formed with various initial arrangements of NA bases and glucuronic acid, and several local minima of potential energy were revealed. Among the resulting structures, those with the highest energy of interactions between the components were selected for each NA base-glucuronic acid pair (Fig. 7).

G - glucuronic acid

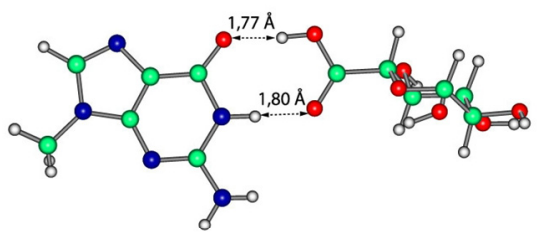

$\Delta \mathrm{E}=-8.54 \mathrm{kcal} / \mathrm{mol}$

C - glucuronic acid

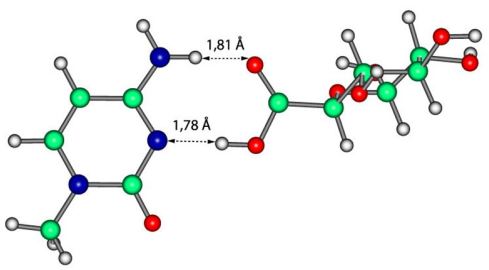

$\Delta \mathrm{E}=-7.79 \mathrm{kcal} / \mathrm{mol}$
A - glucuronic acid

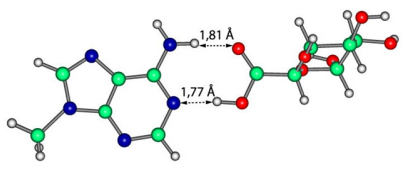

$\Delta \mathrm{E}=-7.91 \mathrm{kcal} / \mathrm{mol}$

$\mathrm{T}$ - glucuronic acid

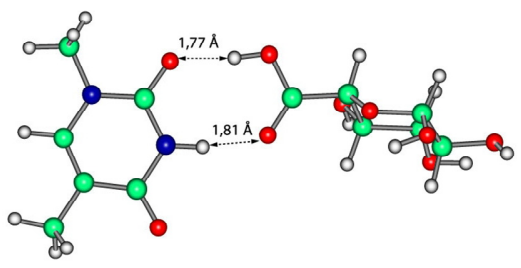

$\Delta \mathrm{E}=-6.39 \mathrm{kcal} / \mathrm{mol}$

Figure 7. Formation of hydrogen bonds between the carboxyl group of glucuronic acid and DNA bases. Quantum chemical computations by the PM3 method.

The complex structure shows clearly that two hydrogen bonds are formed and are nearly in the same plane, as in the case of the T-A interaction. The most important in this situation is that the bonds have approximately the same lengths and binding energies as in the 
complementary pairs AT and GC. In addition, Fig. 7 shows that the interactions of the carboxyl group with the nucleotides are nonequivalent. The interactions with $\mathrm{G}$ and $\mathrm{A}$ are more efficient than with $\mathrm{T}$ and $\mathrm{C}$, which is determined by the geometry of the hydrogen bonds. A hydrogen bond should be of a certain length and orientation relative to other atoms, and the conditions for hydrogen bonding are better in some cases and poorer in some others.

Then, the PM3 method was used to study the possibility of interactions between the bases and the hydroxymethyl group of $\mathrm{N}$-acetylglucosamine. Several initial arrangements of a base and N-acetylglucosamine were analyzed for each of the four bases. Optimization of the initial arrangement allowed several modes of binding. Among the resulting structures, those with the highest energy of interactions were selected. The results are shown in Fig. 8.

$\mathrm{T}$ - N-acetylglucosamine

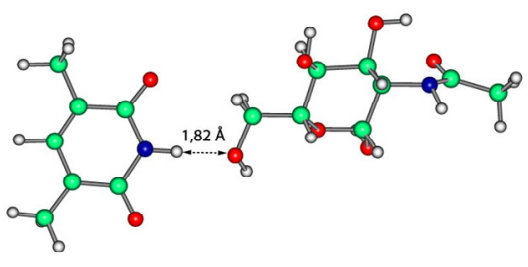

$\Delta \mathrm{E}=-2.90 \mathrm{kcal} / \mathrm{mol}$

G - N- acetylglucosamine

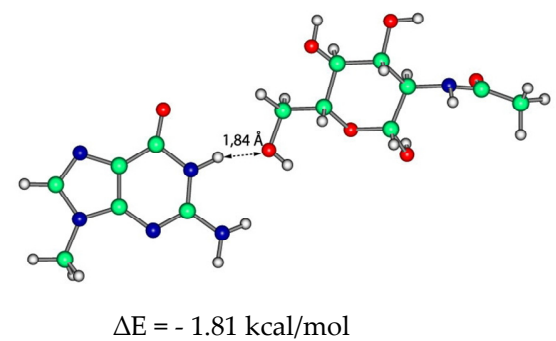

$\mathrm{C}$ - N- acetylglucosamine

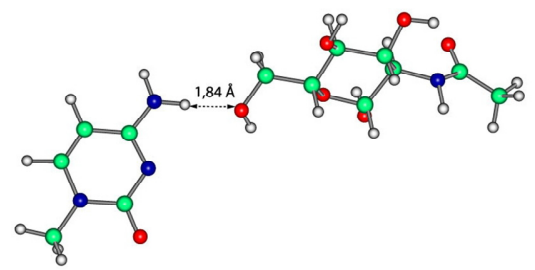

$\Delta \mathrm{E}=-2.04 \mathrm{kcal} / \mathrm{mol}$

A - N-acetylglucosamine

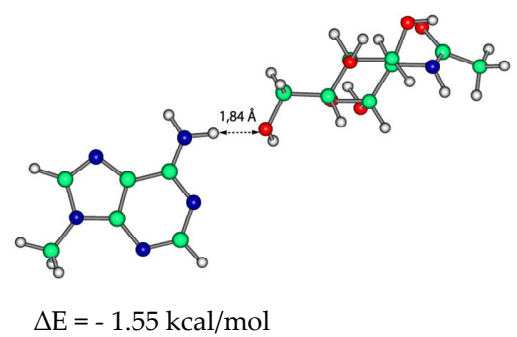

Figure 8. Formation of hydrogen bonds between the hydroxymethyl group of $\mathrm{N}$ - acetylglucosamine and the DNA bases. Quantum chemical computations by the PM3 method.

Let us consider the specifics of hydrogen bonding between the nucleotides and the hydoxymethyl group of $\mathrm{N}$-acetylglucosamine. It is known that hydrogen bonds formed by the hydroxymethyl group are less stable than those formed by the carboxyl group (Roberts J., et al. 1978). As complete optimization of the geometric structures showed, the energy of hydrogen bonds was indeed higher in the complexes of the NA bases with the hydroxymethyl group of $\mathrm{N}$-acetylglucosamine (Fig. 8) than in the complexes with the carboxymethyl group (Fig. 7). Optimization of the geometric structure for complexes of the 
bases with $\mathrm{N}$-acetylglucosamine with various initial arrangements of the interacting groups yielded complexes with one or two hydrogen bonds. Complexes containing one hydrogen bond were most advantageous in terms of energy according to PM3 computations. The nucleotides proved to vary in energy of interaction with the hydroxymethyl group: the interaction was more efficient with $\mathrm{T}$ and $\mathrm{C}$ than with $\mathrm{G}$ and $\mathrm{A}$. The conclusions are as follows.

1. Quantum chemical computations showed that NA bases and the carboxyl or hydroxymethyl group of sugars are capable of forming hydrogen bonds, which are comparable in energy with those occurring in the complementary AT and GC pairs.

2. The bonds are nonequivalent. The carboxyl group forms tighter bonds with purines and less tight bonds with pyrimidines. In contrast, the hydroxymethyl group forms more stable hydrogen bonds with pyrimidines and less stable bonds with purines.

3. The differences in energy computed for hydrogen bonds are insufficient for selection of monosaccharides with necessary structures.

\subsubsection{Quantum chemical analysis of the electron and geometric structures of hydrogen} bonds in complementary pairs of NA bases and polysaccharides by Ab initio calculations in the $6-31 G^{*}$ basis

Let us optimize the geometry of the above complexes by ab initio calculations in the $6-31 \mathrm{G}^{*}$ basis (Table 6).

\begin{tabular}{|c|c|c|c|c|}
\hline & T & A & C & G \\
\hline $\begin{array}{c}\text { Carboxyl group of } \\
\text { glucuronic acid }\end{array}$ & -12.95 & -13.77 & -15.98 & -17.89 \\
\hline
\end{tabular}

Note: Energy $(\mathrm{kcal} / \mathrm{mol})$ was obtained by ab initio calculations in the $6-31 \mathrm{G}^{*}$ basis.

Table 6. Energy of hydrogen bonds between the nucleotides T, A, C, and G and the carboxyl group of glucuronic acid

In general, $a b$ initio calculations confirmed the results obtained by the PM3 method and described in the previous section. The interaction of the carboxyl group of glucuronic acid and the nucleotides is possible, and its energy is sufficient for hydrogen bonding similar to that in the classical complementary DNA pairs. However, the energy of interaction changes with nucleotide in another order: the interaction with the carboxyl group of glucuronic acid is more advantageous with $\mathrm{C}$ and $\mathrm{G}$ and less advantageous with $\mathrm{T}$ and A (Table 6). As for the interaction of the hydroxymethyl group of N-acetylglucosamine with NA bases, the results differed from those obtained by the PM3 method. If the two fragments were initially bonded by one hydrogen bond, like in the case of the interaction between the carboxymethyl group and hydrogen of a base (Fig. 8), then, during optimization, the groups were rotated relative to each other so that the interaction involved the atoms of the monosaccharide ring that by no means can bind to the nucleotide. This is probably explained by the fact that $a b$ initio calculations yield higher estimates of hydrogen bond energy as compared with the PM3 method. As a result, greater energy estimates are obtained for the interactions of $\mathrm{H}$ 
with distant $\mathrm{O}$ and $\mathrm{N}$ and the atoms are brought close together during optimization to form new hydrogen bonds, which are impossible in the double helix.

Thus, $a b$ initio calculations in the $6-31 G^{*}$ basis confirmed that the carboxyl group of glucuronic acid is capable of hydrogen bonding to the bases T, A, G, and C; the two bonds formed in each case are similar to those occurring in the complementary pairs AT and GC.

\subsubsection{PM3 Analysis of the electron and geometric structures of hydrogen bonds in complementary pairs of a NA-glucuronic acid double helix. Selectivity in template synthesis of polysaccharides}

Consider the possibility of polysaccharide synthesis on single-stranded NA. It is clear that, even if some hydrogen bonds are formed between NA bases and monosaccharides, such bonds are not necessarily formed in a polysaccharide-NA double helix because of geometric limitations.

Let us construct two oligomers each consisting of five monomeric units: NA (GCGCA) and oligosaccharide (a HA fragment). As NA, we use the chain analyzed above (Fig. 6). Constructing a chain of five HA monosaccharides, let us rotate the units around the bonds between them so that the carboxyl and hydroxymethyl groups of the resulting chain can be hydrogen bonded to nucleotides. Let us bring the two chains close together so that the distance between groups was 1.5-2.5 $\AA$ as in Figs. 9 and 10, with G and A interacting with the carboxyl group (Fig. 9) and C, with the hydroxymethyl group (Fig. 10). Let us fully optimize the resulting double helix by the PM3 method. The energy of hydrogen bonding in the resulting construct (Figs. 9, 10) is $-7.04 \mathrm{kcal} / \mathrm{mol}$, rather high and almost reaching the energy of interaction in the classical DNA double helix (-8.82 kcal $/ \mathrm{mol}$, Fig. 6).

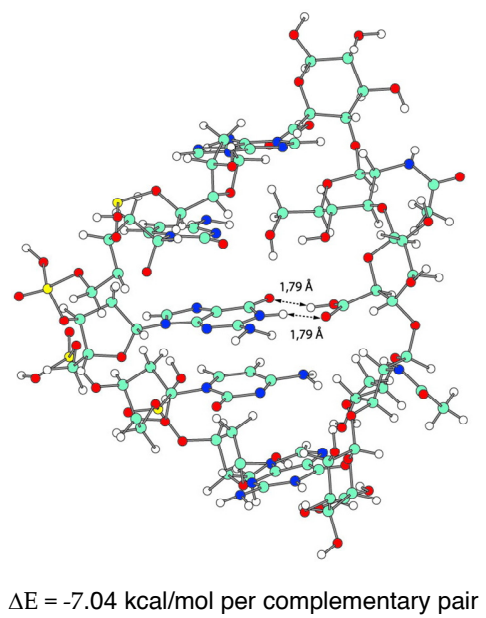

Figure 9. Hydrogen bonding in the complementary pairs G-glucuronic acid, A-glucuronic acid, and C$\mathrm{N}$-acetylglucosamine in a DNA-polysaccharide double helix exemplified by a five-unit chain. Quantum chemical computation by the PM3 method. 


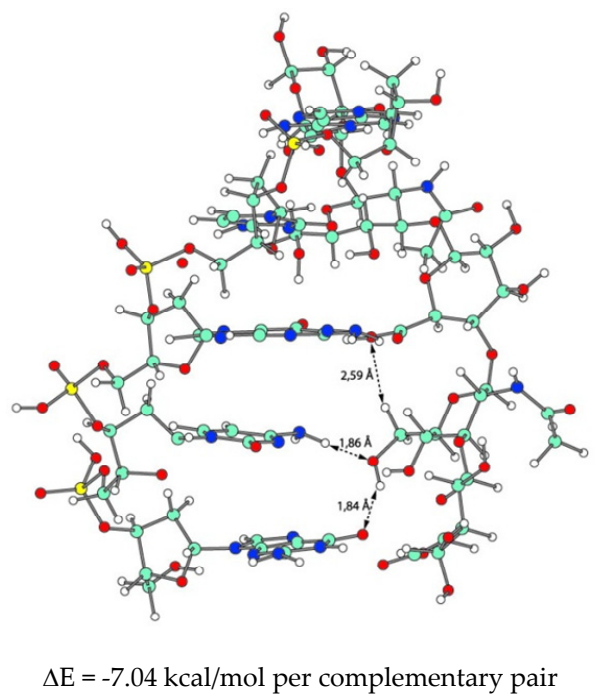

Figure 10. Hydrogen bonding in the complementary pairs G-glucuronic acid, A-glucuronic acid, and $\mathrm{C}-\mathrm{N}$-acetylglucosamine in a DNA-polysaccharide double helix exemplified by a five-unit chain. Quantum chemical computation by the PM3 method. (Another view point).

The interaction purine-glucuronic acid in the NA-polysaccharide double helix was much the same as in isolation: the lengths of the two hydrogen bonds were $1.79 \AA$. However, interesting differences were observed for the pyrimidine- $\mathrm{N}$-acetylglucosamine interaction in the double helix and in isolation. In addition to the only hydrogen bond (1.86 $\AA$ ) formed in isolation (Fig. 10), another hydrogen bond (1.84 $\AA$ ) was formed with O of the neighboring nucleotide in the double helix. Moreover, there was one more, weaker hydrogen bond (2.59 $\AA$ A) directed oppositely. Thus, N-acetylglucosamine also forms two hydrogen bonds with nucleotides of an NA strand, which ensures its sufficiently tight and highly selective interaction with nucleotides of a native NA molecule. In addition, computations were performed for incorrect sequences of monosaccharides. As in the case of incorrect sequences of bases in the DNA double helix, low-energy hydrogen bonds were obtained in this variant or the NA-polysaccharide double helix was not formed at all because the bonds were disadvantageous in terms of energy. The conclusions are as follows.

1. Quantum chemical calculations showed that hydrogen bonds are formed in the complementary pairs purine-glucuronic acid and pyrimidine- $\mathrm{N}$-acetylglucosamine, allowing the formation of a NA-polysaccharide double helix.

2. Geometric parameters of the interacting NA and polysaccharide strands play the major role in selection of particular monosaccharides during putative template synthesis of polysaccharides. The difference observed for the energy of hydrogen bonds is insufficient for selection of monosaccharides with necessary structures.

3. Quantum chemical modeling confirmed that purines are complementary to the carboxyl group and pyrimidines, to the hydroxymethyl group of UDPmonosaccharides. 


\subsection{Spectral analysis and dot hybridization}

Table 7 shows the polysaccharide composition determined biochemically. It should be noted that all polysaccharides were end products of modification, that is, mature glycans. Polyuronides, which consist mostly of uronic acid residues, and amylose, which consists only of glucose residues, can be considered as virtually nonmodified glycans. The hydroxymethyl group at C5 of monosaccharide is substituted with hydrogen in glucuronoxylans. HA and CS have the acetoamide group at C2 of hexose residues. In CS, hydrogen of hydroxyl at C6 is substituted with the sulfo group, which provides an additional partial negative charge to the molecule (Table 7.$)$

\begin{tabular}{|l|c|c|c|c|c|c|c|c|}
\hline \multirow{2}{*}{ Polysaccharide } & \multicolumn{4}{|c|}{ mkg on mg } & \multicolumn{4}{c|}{ in \% } \\
\cline { 2 - 10 } & UA & NS & AAH & OM & UA & NS & AAH & OM \\
\hline Glucuronoxylan & 220 & 771 & 0 & 9 & 22 & 77 & 0 & 1 \\
\hline Polyuronide & 747 & 33 & 0 & 220 & 75 & 3 & 0 & 22 \\
\hline Hyaluronic acid & 535 & 0 & 465 & 0 & 54 & 0 & 46 & 0 \\
\hline Chondroitin sulfate & 413 & 0 & 587 & 0 & 41 & 0 & 59 & 0 \\
\hline Amylose & 0 & 1021 & 0 & 0 & 0 & 100 & 0 & 0 \\
\hline
\end{tabular}

Note: UA, uronic acid (on Dishe); NS, neutral sugar (on anthrone method); AAH, aminoacetylhexoses(AAH=1000$\mathrm{UA})$; OM, other monosaccharides (OM=1000-UA-NS).

Table 7. Characterization of the composition of polysaccharides used in experiments

Electrophoretic analysis of polysaccharides used in experiments is illustrated in Fig. 11. It is seen that polysaccharides were sufficiently pure, which was important for our study.

The results shown in Figs. 12A, 12B, and 13A demonstrate that the absorption and CD spectra remained much the same when poly $(\mathrm{dC})$ was combined with oat polyuronides or poly(dA), with amylose. This finding suggests that these polynucleotides and polysaccharides do not form sufficiently tight complexes.

When poly $(\mathrm{dA})$ was combined with oat polyuronides or poly $(\mathrm{dC})$, with amylose, a decrease in amplitude was observed on both the absorption and CD spectra (Figs. 12C, 13B, 13C). The decrease in the peak intensity of the $C D$ spectrum and the simultaneous decrease in the amplitude of peak absorption (a hypochromic effect) can result from an increase in the degree of spiralization and the twist of the polynucleotide (Blagoi Yu.P., et al. 1999), suggesting the formation of a single-stranded polynucleotide-polysaccharide complex. It should be noted that the amplitude of the absorption spectra changed by $9-11 \%$ in this case. Since the hyperchromic effect of double-stranded DNA (poly(dA)-poly(dT)) in $0.3 \mathrm{M} \mathrm{NaCl}$ was $27-30 \%$ (Figs. 14A, 14B), which agreed with published data (Yang J.T., et al. 1969), the change observed in our experiment accounted for $30-35 \%$ of the hyperchromic effect characterizing complete base pairing. 


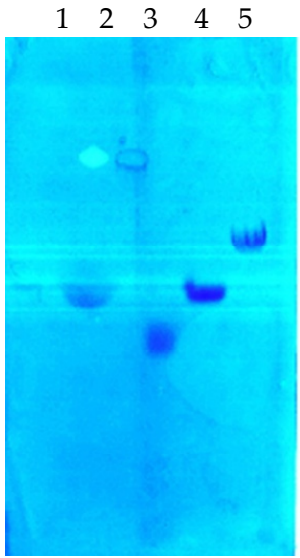

1 , oat polyuronides

3, HS

2 , garlic glucuronoxylans

$4, \mathrm{CS}$

5, HA

Figure 11. Electrophoresis of polysaccharides in cellulose acetate bands in $0.1 \mathrm{~N} \mathrm{HCl}$.
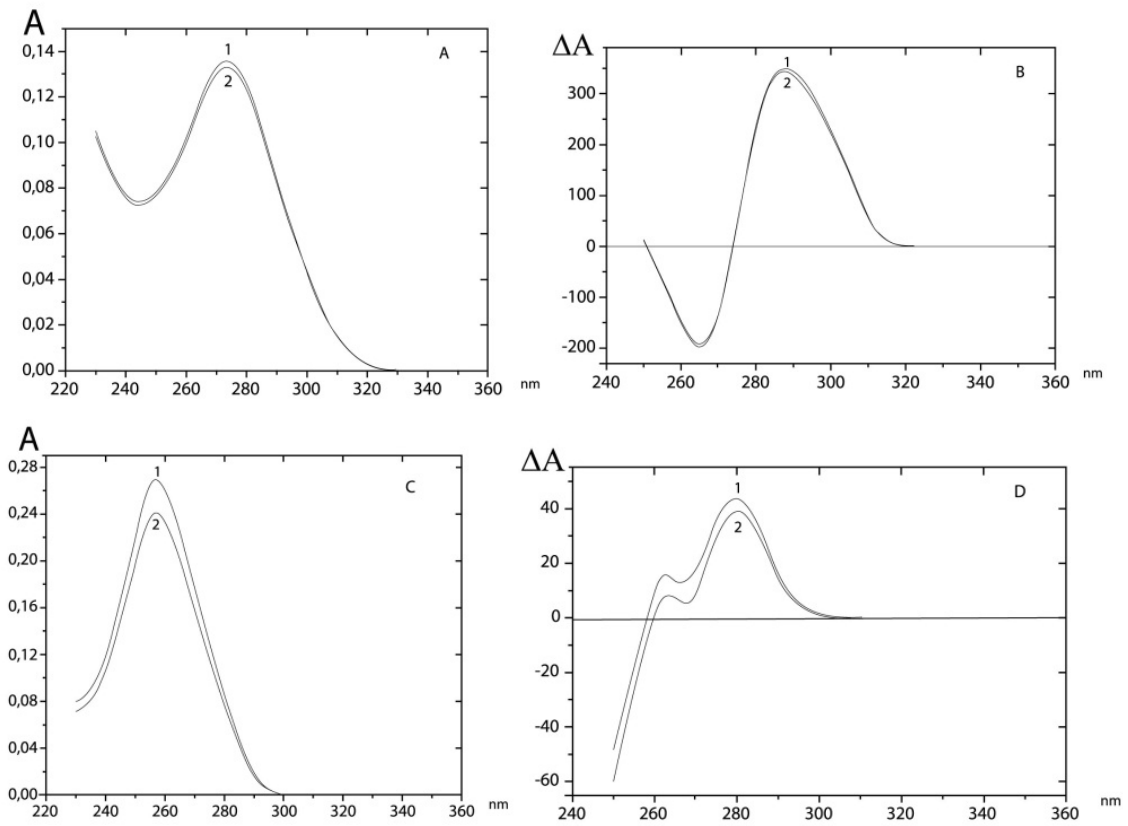

Figure 12. A. Absorption spectrum of poly $(\mathrm{dC})$ in the absence (curve 1) or presence (curve 2) of polyuronide $(\mathrm{PU}), \mathrm{r}=2$. $(\mathrm{r}-$ is hereafter the ratio of polysaccharide units to the molar concentration of nucleotides.) B. CD spectrum of poly $(\mathrm{dC})$ in the absence (curve 1) or presence (curve 2) of PU, $r=2$. C. Absorption spectrum of poly $(\mathrm{dA})$ in the absence (curve 1) or presence (curve 2) of $\mathrm{PU}, \mathrm{r}=1$. D. CD spectrum of poly $(\mathrm{dA})$ in the presence (curve 1) or absence (curve 2) of $\mathrm{PU}, \mathrm{r}=1$. 



Figure 13. A. Absorption spectrum of poly $(\mathrm{dA})$ in the absence (curve 1) or presence (curve 2) of amylose $(\mathrm{AM}), \mathrm{r}=2$. B. Absorption spectrum of poly $(\mathrm{dC})$ in the absence (curve 1) or presence (curves 2 , 3) of AM; $r=0.5(1), r=1(2), r=2$ (3). C. CD spectrum of poly(dC) in the absence (curve 1) or presence (curve 2) of AM, $r=2$.
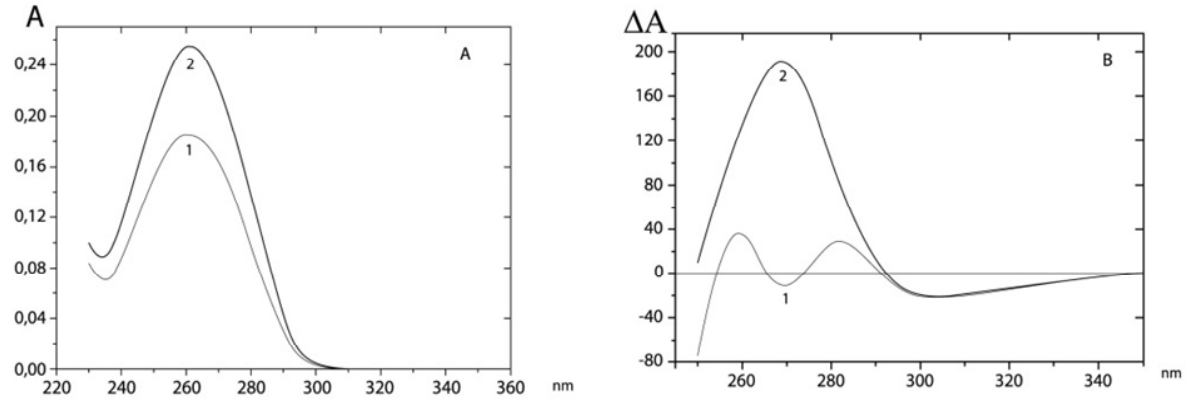

Figure 14. A. Absorption spectra of poly $(\mathrm{dA})-(\mathrm{dT}) 16$ (curve 1) and an equimolar mixture of poly $(\mathrm{dA})$ and $(\mathrm{dT})_{16}$ (curve 2$), r=1$. B. CD spectra of of poly $(\mathrm{dA})-(\mathrm{dT})_{16}$ (curve 1 ) and an equimolar mixture of poly $(\mathrm{dA})$ and $(\mathrm{dT})_{16}$ (curve 2), $\mathrm{r}=1$. 
The results shown in Figs. 15A and 15B demonstrate that CS does not form a tight complex with DNA, because the DNA absorption spectrum was almost completely restored after annealing in the presence of CS. Another situation was observed with HA (Fig. 15A): a hyperchromic effect of about $10-11 \%$ was observed in this case. This finding suggests complexation of HA with DNA regions, because such complexation should prevent the DNA duplex from being restored after annealing in the presence of HA.
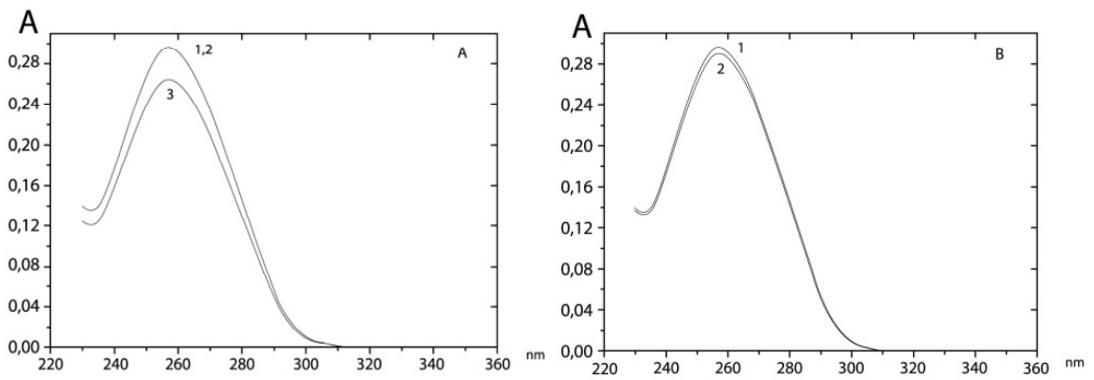

Figure 15. A. Absorption spectra of calf thymus DNA in the absence (curve 1, before annealing; curve 2, after annealing) or presence (curve 3, after annealing) HA; $r=1$. B. Absorption spectra of calf thymus DNA in the presence of CS before (curve 1) and after (curve 2) annealing, $r=1$.

Dot hybridization showed that DNAs of all organisms specifically binds with oligodeoxyribonucleotide probes (Fig. 16). Although the method is semiquantitative, it is possible to state that the GC tandem repeat has more complementary sequences in DNA as compared with monopurine (A) or monopyrimidine (C) homopolymers. For instance, poly $(\mathrm{dT})$ and poly $(\mathrm{dGC})$ arrays are rather abundant in human DNA, while poly(dG) occur in a smaller amount. Garlic DNA showed a greater amount of poly $(\mathrm{dG})$ as compared with human DNA. This result agrees with the modern views of the plant genome (Zelenin A.V. 2003).

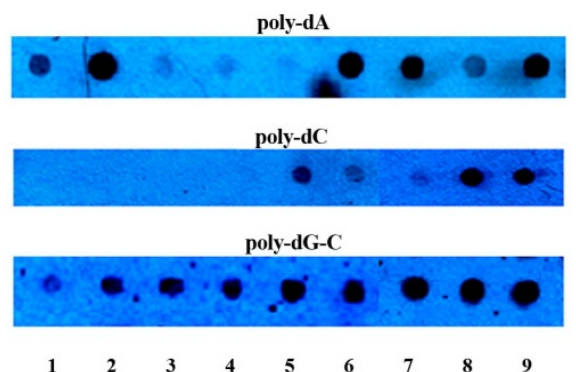
1. glucuronoxylans
6. garlic DNA
2. polyuronides
7. human DNA
3. CS
8. fish DNA
4. HA
9. calf thymus DNA
5. amylase

Figure 16. Dot hybridization of polysaccharides and DNA with oligodeoxyribonucleotide probes. The membrane was autoradiographed. 
Since we aimed at studying the possibility of specific bonding between NA and polysaccharides, the results obtained with DNA were used exclusively as a control.

\begin{tabular}{|l|c|c|c|c|c|c|}
\hline \multirow{2}{*}{$\begin{array}{l}\text { Biopolymer } \\
\text { in a dot }\end{array}$} & \multicolumn{3}{|c|}{ Dot radioactivity, cpm } & \multicolumn{3}{c|}{$\%$ of maximal count } \\
\cline { 2 - 7 } & $\begin{array}{c}\text { Poly(dA) } \\
\text { probe }\end{array}$ & $\begin{array}{c}\text { Poly(dC) } \\
\text { probe }\end{array}$ & $\begin{array}{c}\text { Poly(dGC) } \\
\text { probe }\end{array}$ & $\begin{array}{c}\text { Poly(dA) } \\
\text { probe }\end{array}$ & $\begin{array}{c}\text { Poly(dC) } \\
\text { probe }\end{array}$ & $\begin{array}{c}\text { Poly(dGC) } \\
\text { probe }\end{array}$ \\
\hline Glururonoxylans & 165 & 47 & 40 & 33 & 5 & 26 \\
Polyuronides & 496 & 18 & 107 & $\underline{\mathbf{1 0 0}}$ & 2 & 69 \\
HA & 102 & 8 & 155 & 20 & 0 & $\underline{\mathbf{1 0 0}}$ \\
CS & 2 & 65 & 97 & 0 & 7 & 63 \\
Amylose & 61 & 868 & 40 & 12 & $\underline{\mathbf{1 0 0}}$ & 69 \\
\hline Garlic DNA & 860 & 466 & 390 & 34 & 15 & 38 \\
Human DNA & 925 & 182 & 394 & 36 & 6 & 38 \\
Fish DNA & 2556 & 2990 & 1034 & 100 & 100 & 100 \\
Calf thymus DNA & 2161 & 1570 & 979 & 85 & 52 & 95 \\
\hline
\end{tabular}

Table 8. Radioactivity of dots of polysaccharides and DNA after hybridization with purine-pyrimidine DNA probes

The results of autoradiography (Fig. 16, Table 8) demonstrated that the poly(dA) probe specifically hybridized with oat polyuronides to an extent comparable with that of DNA (garlic DNA). The poly $(\mathrm{dC})$ probe specifically hybridized to a high extent with potato amylose. Since oat polyuronides consist almost exclusively of hexuronic acid residues and potato amylose, of hexose residues, we observed significant specific hybridization of pyrimidines (exemplified by C) with polyhexoses and purines (exemplified by A) with polyuronic acids.

The data obtained with glucoronoxylans were interpreted according to the same principle. It is known that glucuronoxylans contains about one carboxyl group per four neutral saccharide residues; i.e., the content of carboxyl groups is three or four times lower than in polyuronides. Hybridization of glucuronoxylans with poly(dA) was indeed about threefold lower than that of polyuronides.

The regular tandem poly(dGC) probe efficiently hybridized with all polysaccharides and especially with GAG. The highest hybridization efficiency was observed with HA. This finding agrees with the tandem structure of HA consists of glucose-glucuronic acid dimers, which interacted with the purine-pyrimidine dimers of the synthetic probe NA. 


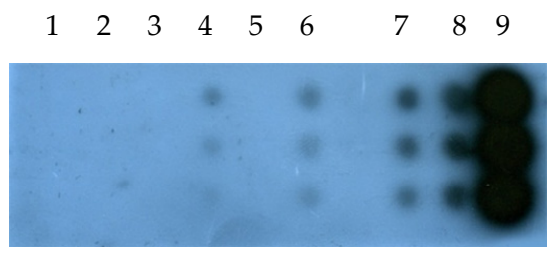

1, garlic glucuronoxylans

2 , oat polyuronides

3, animal CS

4, animal HA

5 , potato amylose
6, garlic DNA

7, fish DNA

8, phage DNA

9 , calf DNA

Figure 17. Dot hybridization of polysaccharides and DNAs with calf thymus DNA. The membrane was autoradiographed.

Figure 17 shows the results of dot hybridization of polysaccharides and DNAs of various organisms with fragmented calf thymus DNA. The highest radioactivity was observed in dot 9, i.e., for self-hybridization of calf genomic DNA. In addition, repetitive elements of calf thymus DNA detected homologous sequences in virtually all genomic DNAs examined. Of all polysaccharides, only HA (dot 4) had matching structures in calf thymus DNA and formed specific complexes similar in radioactivity to DNA-DNA complexes.

\subsection{Glycan biosynthesis in rat liver}

The profile of elution of rat liver and marker polysaccharides from DEAE cellulose with a $\mathrm{NaCl}$ gradient is shown in Fig. 18. As markers, we used homopolymers of uronic acid (oat polyuronides) and glucose (potato amylose).



Figure 18. Profiles of elution of rat liver and marker polysaccharides from DEAE cellulose with a $\mathrm{NaCl}$ gradient.

As evident from the elution profile, the rat liver contains a complex spectrum of polysaccharides. Analysis with the marker homoglycan amylose, consisting of glucose residues, showed that polymers with a similar structure of neutral sugars are absent from 
rat liver glycans isolated by our method (such polymers were eluted from the column during washing). Glucose homoglycans were eluted with $0.01 \mathrm{M} \mathrm{NaCl}$. The first peak of liver glycans was detected at $0.02-0.03 \mathrm{M} \mathrm{NaCl}$. With $\mathrm{NaCl}$ increasing to $0.15 \mathrm{M}$, we eluted polysaccharides with a negative charge greater than in polymers of neutral sugars and lower than in the $0.25 \mathrm{M} \mathrm{NaCl}$ fraction, which mostly consisted of HA, as commonly known (Zimnitskii A.N., et al. 2004). The fractions 0.7 and $1.5 \mathrm{M} \mathrm{NaCl}$ exemplified a classical separation of CS and HS. As expected, highly charged oat polyuronides were eluted at the highest ionic strength, at about $1.2 \mathrm{M} \mathrm{NaCl}$.

The results of quantitating uronic acids, hexosamines, and NS in the chromatographic fractions are summarized in Table 9.

\begin{tabular}{|l|c|c|c|}
\hline \multicolumn{1}{|c|}{ Fraction } & Uronic acids & Hexosamines & Neutral sugars \\
\hline $0.15 \mathrm{M}$ & $34.1 \pm 0.3$ & $2.0 \pm 0.1$ & $48.5 \pm 0.3$ \\
\hline $0.25 \mathrm{M}$ & $8.3 \pm 0.1$ & $7.1 \pm 0.9$ & - \\
\hline $0.7 \mathrm{M}$ & $61.5 \pm 0.7$ & $63.7 \pm 0.6$ & $2.1 \pm 0.2$ \\
\hline $1.5 \mathrm{M}$ & $64.2 \pm 0.5$ & $57.9 \pm 6.4$ & $2.2 \pm 0.2$ \\
\hline
\end{tabular}

Table 9. Concentrations $(\mu \mathrm{g} / \mathrm{ml})$ of uronic acids, hexosamines, and NS in fractions of liver polysaccharides of intact rats (rats were not subjected to external influence)

In the $0.25,0.7$, and $1.5 \mathrm{M}$ fractions, the ratio uronic acids : hexosamines was about 1:1, which is characteristic of HA, CS, and HS and agrees with published data. A minor amount of NS detected in the 0.7 and $1.5 \mathrm{M}$ fractions could be explained by the presence of a trisaccharide fragment linking GAG with the core protein in proteoglycans.

\begin{tabular}{|l|c|c|c|}
\hline Subfraction & Nuclei & Microsomes & Homogenate \\
\hline $0.02 \mathrm{M}$ & $265 \pm 18 / 67 \pm 7$ & $108 \pm 12 / 52 \pm 7$ & $128 \pm 15 / 67 \pm 8$ \\
\hline $0.06 \mathrm{M}$ & $36 \pm 5 / 7 \pm 2$ & $24 \pm 3 / 40 \pm 6$ & $34 \pm 6 / 22 \pm 3$ \\
\hline $0.15 \mathrm{M}$ & $20 \pm 3 / 6 \pm 2$ & $18 \pm 2 / 50 \pm 6$ & $33 \pm 5 / 81 \pm 11$ \\
\hline
\end{tabular}

Table 10. Contents ( $\mu$ g per $\mathrm{g}$ tissue) of NS/uronic acids in the $0.15 \mathrm{M} \mathrm{NaCl}$ saccharide fractions of cell nuclei, microsomes, and a homogenate of the liver of intact rats

\begin{tabular}{|l|c|c|c|}
\hline Subfraction & Nuclei & Microsomes & Homogenate \\
\hline $0.02 \mathrm{M}$ & 0.76 & 1.40 & 1.60 \\
\hline $0.06 \mathrm{M}$ & 1.44 & 5.0 & 1.94 \\
\hline $0.15 \mathrm{M}$ & 1.57 & 8.30 & 7.4 \\
\hline
\end{tabular}

Table 11. Uronic acids per neutral trisaccharide in the $0.15 \mathrm{M} \mathrm{NaCl}$ saccharide fractions of cell nuclei, microsomes, and a homogenate of the liver of intact rats

The $0.15 \mathrm{M}$ fraction contained glycans enriched in neutral sugars (Table 9). Three subfractions could be isolated in this fraction: the first peak eluted up to $0.02 \mathrm{M} \mathrm{NaCl}$, the 
second peak eluted up to $0.06 \mathrm{M} \mathrm{NaCl}$, and a plateau eluted up to $0.15 \mathrm{M} \mathrm{NaCl}$. The primary structure of polysaccharide fragments of this fraction is characterized in Tables 10 and 11. As evident from Table 11, nuclear oligosaccharides had the NS : uronic acid ratio similar to $3: 1$, suggesting the presence of neutral trisaccharides containing no more than one uronic acid residue. Both microsomal and homogenate fractions harbored neutral oligosaccharides containing more than one uronic acid residue per trisaccharide, the proportion of uronic acids increasing sixfold from the 0.02 to the $0.15 \mathrm{M}$ subfraction. This finding testifies that uronic acid is linked to trisaccharides mostly in cell microsomes. Only one uronic acid residue per trisaccharide is linked in cell nuclei.

\begin{tabular}{|l|c|}
\hline Substance & Content \\
\hline DNAn $_{n}$ & $9.26 \pm 0.30$ \\
\hline $0.15 \mathrm{M}_{n}$ fraction of PS (Fig. 18) & $1.42 \pm 0.12$ \\
\hline HAn & $1.46 \pm 0.14$ \\
\hline C $_{n}$ & $2.56 \pm 0.16$ \\
\hline HS & $0.68 \pm 0.07$ \\
\hline DNA $_{h}$ & $167.61 \pm 6.94$ \\
\hline $0.15 \mathrm{M}_{h}$ fraction of PS (Fig. 18) & $42.02 \pm 4.13$ \\
\hline HAh & $23.74 \pm 3.35$ \\
\hline CSh & $23.60 \pm 3.31$ \\
\hline HSh & $13.45 \pm 1.22$ \\
\hline
\end{tabular}

Note: Subscripts $\mathrm{n}$ and $\mathrm{h}$ correspond to the nuclear fraction and the homogenate, respectively.

Table 12. Contents ( $\mu \mathrm{g}$ per $\mathrm{g}$ tissue) of DNA and GAG in the nuclear fraction and the homogenate of the liver of intact rats

The DNA content and the GAG composition in the nuclear fraction and the homogenate of the rat liver are shown in Table 12. The total GAG content was $6.12 \mu \mathrm{g}$ per $\mathrm{g}$ tissue in the nuclear fraction and $102.81 \mu \mathrm{g}$ per $\mathrm{g}$ tissue in the homogenate. Nuclear GAG contained $0.15 \mathrm{M}$ fraction PS to $23.20 \%$, HA to $23.86 \%$, CS to $41.83 \%$, and HS to $11.11 \%$. GAG of the homogenate contained $0.15 \mathrm{M}$ fraction PS to $40.87 \%$, HA to $23.09 \%$, CS to $22.95 \%$, and HS to $13.08 \%$.

Our isolation procedure yielded about $5 \%$ of nuclei in the intact form. The remaining nuclei, along with their contents, were in the liver homogenate.

Correlation analysis was performed to study the association between the biochemical parameters and the time after a glucose load. Since the empirical sample was small $(n<30)$, we computed Pearson parametric empirical correlation coefficients and Spearman nonparametric rank correlation coefficients. The results are summarized in Tables 13-15.

As Table 13 shows, a strong positive correlation was observed between time and HS content in the homogenate $(\mathrm{r}=0.81)$ and between the contents of HS in nuclei and the $0.15 \mathrm{M}$ fraction in the homogenate $(\mathrm{r}=0.95)$ and a strong negative correlation between the contents of the $0.15 \mathrm{M}$ fraction and DNA in nuclei $(\mathrm{r}=-0.71)$. 


\begin{tabular}{|l|c|c|c|c|c|c|c|c|c|c|c|}
\hline & $\mathrm{t}(\mathrm{min})$ & DNAn & $0.15 \mathrm{Mn}$ & $\mathrm{HAn}$ & $\mathrm{CSn}$ & $\mathrm{HSn}$ & $\mathrm{DNAh}$ & $0.15 \mathrm{Mh}$ & $\mathrm{HAh}$ & $\mathrm{CSh}$ & $\mathrm{HSh}$ \\
\hline $\mathrm{t}(\mathrm{min})$ & 1.00 & -0.01 & -0.28 & -0.31 & -0.35 & -0.54 & -0.53 & -0.34 & -0.24 & -0.58 & $\mathbf{0 . 8 1}$ \\
\hline DNAn & -0.01 & 1.00 & $\mathbf{- 0 . 7 1}$ & -0.41 & 0.62 & 0.54 & -0.09 & 0.53 & -0.19 & 0.09 & 0.35 \\
\hline $0.15 \mathrm{Mn}$ & -0.28 & $\mathbf{- 0 . 7 1}$ & 1.00 & 0.45 & -0.08 & -0.12 & 0.29 & -0.05 & -0.13 & 0.37 & -0.47 \\
\hline HAn & -0.31 & -0.41 & 0.45 & 1.00 & 0.24 & 0.07 & -0.18 & -0.09 & 0.30 & 0.37 & -0.55 \\
\hline CSn & -0.35 & 0.62 & -0.08 & 0.24 & 1.00 & 0.66 & 0.06 & 0.54 & 0.03 & 0.50 & -0.30 \\
\hline HSn & -0.54 & 0.54 & -0.12 & 0.07 & 0.66 & 1.00 & 0.61 & $\mathbf{0 . 9 5}$ & 0.24 & 0.69 & -0.24 \\
\hline DNAh & -0.53 & -0.09 & 0.29 & -0.18 & 0.06 & 0.61 & 1.00 & 0.64 & 0.37 & 0.43 & -0.42 \\
\hline $0.15 \mathrm{Mh}$ & -0.34 & 0.53 & -0.05 & -0.09 & 0.54 & $\mathbf{0 . 9 5}$ & 0.64 & 1.00 & 0.12 & 0.62 & -0.03 \\
\hline HAh & -0.24 & -0.19 & -0.13 & 0.30 & 0.03 & 0.24 & 0.37 & 0.12 & 1.00 & -0.18 & -0.50 \\
\hline CSh & -0.58 & 0.09 & 0.37 & 0.37 & 0.50 & 0.69 & 0.43 & 0.62 & -0.18 & 1.00 & -0.34 \\
\hline HSh & $\mathbf{0 . 8 1}$ & 0.35 & -0.47 & -0.55 & -0.30 & -0.24 & -0.42 & -0.03 & -0.50 & -0.34 & 1.00 \\
\hline
\end{tabular}

Note: Significant correlation coefficients are in bold.

Table 13. Pearson empirical correlation coefficients $(r)$ between the time after a glucose load and the DNA and GAG contents in the rat liver

\begin{tabular}{|l|c|c|c|c|c|c|c|c|c|c|c|}
\hline & $\begin{array}{c}\mathrm{t} \\
(\mathrm{min})\end{array}$ & DNAn & $0.15 \mathrm{Mn}$ & HAn & CSn & HSn & DNAh & $0.15 \mathrm{Mh}$ & HAh & CSh & HSh \\
\hline $\mathrm{t}(\mathrm{min})$ & 1.00 & -0.15 & -0.15 & -0.15 & -0.34 & -0.47 & -0.68 & -0.15 & -0.32 & -0.49 & 0.63 \\
\hline DNAn & -0.15 & 1.00 & $\mathbf{- 0 . 7 4}$ & -0.36 & 0.54 & 0.48 & -0.20 & 0.35 & 0.01 & -0.01 & 0.34 \\
\hline $0.15 \mathrm{Mn}$ & -0.15 & $\mathbf{- 0 . 7 4}$ & 1.00 & 0.53 & 0.07 & -0.10 & 0.31 & 0.10 & -0.04 & 0.41 & -0.40 \\
\hline HAn & -0.15 & -0.36 & 0.53 & 1.00 & 0.45 & 0.23 & 0.19 & 0.12 & 0.40 & 0.40 & -0.50 \\
\hline CSn & -0.34 & 0.54 & 0.07 & 0.45 & 1.00 & 0.67 & 0.14 & 0.62 & 0.26 & 0.50 & -0.07 \\
\hline HSn & -0.47 & 0.48 & -0.10 & 0.23 & 0.67 & 1.00 & 0.30 & $\mathbf{0 . 8 4}$ & -0.04 & $\mathbf{0 . 8 4}$ & 0.16 \\
\hline DNAh & -0.68 & -0.20 & 0.31 & 0.19 & 0.14 & 0.30 & 1.00 & 0.19 & 0.61 & 0.38 & -0.45 \\
\hline $0.15 \mathrm{Mh}$ & -0.15 & 0.35 & 0.10 & 0.12 & 0.62 & $\mathbf{0 . 8 4}$ & 0.19 & 1.00 & -0.24 & $\mathbf{0 . 7 4}$ & 0.36 \\
\hline HAh & -0.32 & 0.01 & -0.04 & 0.40 & 0.26 & -0.04 & 0.61 & -0.24 & 1.00 & -0.17 & -0.49 \\
\hline CSh & -0.49 & -0.01 & 0.41 & 0.40 & 0.50 & $\mathbf{0 . 8 4}$ & 0.38 & $\mathbf{0 . 7 4}$ & -0.17 & 1.00 & 0.00 \\
\hline HSh & 0.63 & 0.34 & -0.40 & -0.50 & -0.07 & 0.16 & -0.45 & 0.36 & -0.49 & 0.00 & 1.00 \\
\hline
\end{tabular}

Note: Significant correlation coefficients are in bold.

Table 14. Spearman rank correlation coefficients $(R)$ between the time after a glucose load and the DNA and GAG contents in the rat liver

Table 14 shows three strong correlations: a negative one between the contents of the $0.15 \mathrm{M}$ fraction and DNA in nuclei and positive correlations between the HS content in nuclei and the CS content in the homogenate and between the contents of the $0.15 \mathrm{M}$ fraction and CS in the homogenate $(R=0.74)$.

To identify latent variables uniting the parameters under study, factor analysis was performed using the Varimax procedure (Table 15). 


\begin{tabular}{|l|c|c|c|}
\hline Parameter & Factor 1 & Factor 2 & Factor 3 \\
\hline $\mathrm{t}(\mathrm{min})$ & -0.490 & 0.494 & -0.473 \\
\hline $\mathrm{DNAn}$ & 0.656 & 0.656 & -0.189 \\
\hline $0.15 \mathrm{Mn}$ & -0.064 & $\mathbf{- 0 . 8 5 1}$ & -0.009 \\
\hline $\mathrm{HAn}$ & 0.054 & $\mathbf{- 0 . 7 6 8}$ & 0.019 \\
\hline $\mathrm{CSn}$ & $\mathbf{0 . 8 0 4}$ & -0.064 & -0.063 \\
\hline $\mathrm{HSn}$ & $\mathbf{0 . 9 1 3}$ & 0.061 & 0.361 \\
\hline DNAh & 0.386 & -0.106 & $\mathbf{0 . 7 2 8}$ \\
\hline $0.15 \mathrm{Mh}$ & $\mathbf{0 . 8 6 3}$ & 0.159 & 0.279 \\
\hline HAh & -0.112 & 0.001 & $\mathbf{0 . 8 6 6}$ \\
\hline CSh & $\mathbf{0 . 7 7 6}$ & -0.500 & -0.041 \\
\hline HSh & -0.146 & 0.692 & -0.573 \\
\hline Proper factor value & 3.687 & 2.762 & 2.083 \\
\hline $\begin{array}{l}\text { Variance portion } \\
\text { accounted for by the } \\
\text { factor }\end{array}$ & 0.335 & 0.251 & 0.189 \\
\hline
\end{tabular}

Note: Significant correlations between the parameter and the factor are in bold.

Table 15. Factor analysis (Varimax) of the time after a glucose load and the DNA and GAG contents in the rat liver

As evident from Table 15, Factor 1 included CSn, HSn, the $0.15 \mathrm{Mh}$ fraction, and CSh. Factor 2 included the $0.15 \mathrm{Mn}$ fraction and HAn. Factor 3 included DNAh and HAh.

The most important result of correlation analysis is that strong linear correlations were observed between the time after a glucose load and the content of $\mathrm{HS}$ in the liver homogenate and between the contents of the $0.15 \mathrm{M}$ fraction and DNA in the nucleus. In the first case, we record an increase in the time of synthesis of GAG modified to the greatest extent (at least two sulfo groups per disaccharide fragment). This result was conformed by factor analysis, since the time and the HS content in the homogenate are components of one factor. In the second case, we possibly establish a functional relationship between synthesis of nuclear oligosaccharides contained in the $0.15 \mathrm{M}$ fraction and the genetic apparatus of the cell. The two biopolymers involved belong to different classes, but their biosynthesis utilizes the same initial substrate, glucose. The strong negative correlation suggests competition for the initial substrate between the two biosynthetic pathways. Since the nuclear DNA content was constant under the conditions of our experiments, the negative correlation suggests that synthesis of saccharides belonging to the $0.15 \mathrm{M}$ fraction increases when free glucose enters cells in considerable amounts. This assumption is supported by the results shown in Fig. 19.

The composition of the $0.15 \mathrm{M}$ fraction and GAG in nuclei, microsomes, and the homogenate is shown in Fig. 20. It is seen that nuclear GAG are enriched in CS (about 42\%), which agrees with the accepted views (Silbert J.E. Sugumaran G ., 1995). Homogenate GAG consist mostly of HA and CS (about 23\%). In microsomes, all GAG types occur in nearly equal proportions 
(about 12\%). The results obtained for the $0.15 \mathrm{M}$ fraction, which consists of three main subfractions (Table 11), are shown in Fig. 21. The fraction occurred at a high content (about $60 \%$ ) in microsomes, while its content in the nucleus was no more than $23 \%$. The homogenate was intermediate between nuclei and microsomes in the content of this fraction.

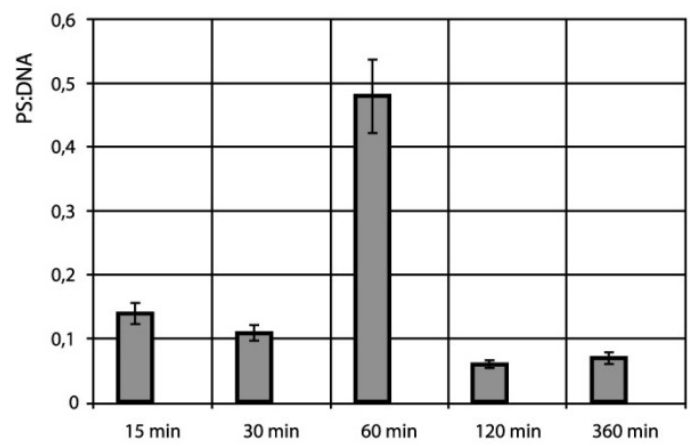

Figure 19. Accumulation of polysaccharides (PS) of the $0.15 \mathrm{M}$ fraction in the nucleus. The content of the fraction was normalized with respect to the DNA content.



Figure 20. Relative contents (\%) of polysaccharides in nuclei, microsomes, and the homogenate of the rat liver.

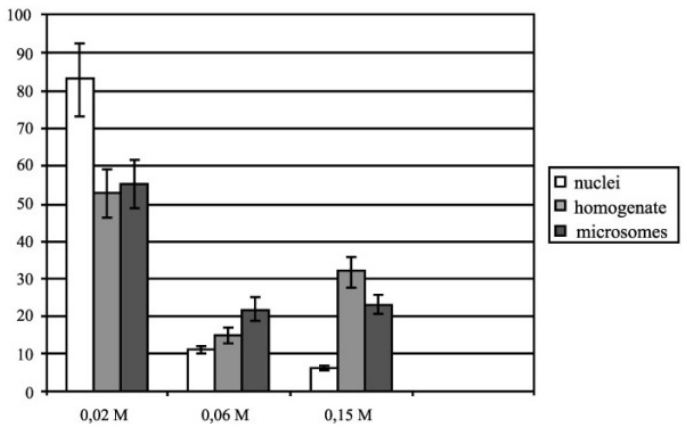

Figure 21. Relative contents (\%) of polysaccharides differing in the portion of neutral sugars in the 0.15 $\mathrm{M}$ fractions of nuclei, microsomes, and the homogenate of the rat liver. 
To study biosynthesis of polysaccharide fragments, we analyzed the time course of incorporating radiolabeled glucose in polysaccharide chains (Fig. 22).

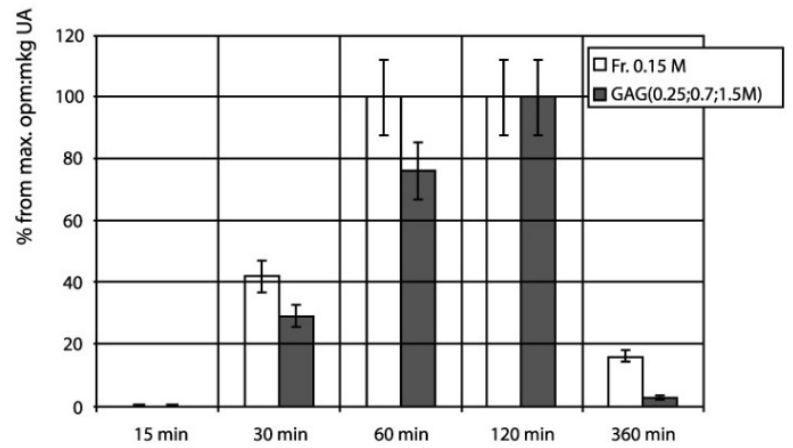

Figure 22. Growth to the maximal specific radioactivity of polysaccharides as dependent on the time of label presence in rats. The maximal specific radioactivity was taken as $100 \%$ for each fraction.

The highest radioactivity of the $0.15 \mathrm{M}$ fraction was detected $60-75 \mathrm{~min}$ after a glucose load, while mature GAG (fraction 0.25-1.5 M) showed the highest radioactivity after $120 \mathrm{~min}$. Thus, initiation of glycan synthesis is probably associated with the $0.15 \mathrm{M}$ fraction, enriched in neutral oligosaccharides, which is consistent with common views of proteoglycan biosynthesis.

To identify the subcellular structures where generation of a polysaccharide chain is initiated, we studied the dynamics of label incorporation in the nuclear and microsomal fractions of the rat liver. The results of this experiment are shown in Fig. 23.



Figure 23. Dynamics of accumulation of radiolableled glucose in the nuclear and microsomal fractions of the rat liver. As $100 \%$, we used the radioactivity averaged over all fractions and all time points.

As Fig. 23 demonstrates, the label became detectable in cell structures $30 \mathrm{~min}$ after a glucose load. The label accumulated to the highest content in both fractions within $1 \mathrm{~h}$ of the experiment. It should be noted that, in the first hour, the accumulation rate was higher in the nuclear fraction (radioactivity 53\% compared with $44 \%$ in the microsomal fraction). 
After $120 \mathrm{~min}$ of the experiment, the microsomal fraction accumulated a greater amount of the label as compared with nuclei (29 and 12\%, respectively). After $3 \mathrm{~h}$, the label was again accumulated more intensely in nuclear structures (33\% compared with $26 \%$ in microsomes).

\section{Discussion}

Our results demonstrate that polysaccharides are similar to NA in many aspects. To a great extent, this is a consequence of the fact that NA is a polymer of ribose or deoxyribose having a base as a side-chain substituent. Some polysaccharides (e.g., HA, amylose, cellulose) are themselves capable of forming helical structures similar to NA.

Quantum chemical computations revealed the possibility of selective bonding between UDPuronic acids and purines and between UDP-hexoses and pyrimidines contained in NA. The bonding strength per monomer unit in the polysaccharide-NA complex is similar to that computed for the NA double helix. This selectivity allows us to assume a binary genetic code for polysaccharides on the basis of the above principles in addition to the commonly accepted genetic code for amino acids. Quantum chemical computations were supported by the results of dot hybridization and spectral analysis of NA-polysaccharide complexes.

The spectrophotometric studies showed that amylose selectively binds with polypyrimidines (poly $(\mathrm{dC})$ ) while polyuronides bind with polypurines (poly $(\mathrm{dA})$ ). As well known, amylose is a homopolysaccharide of hexose and polyuronide, of hexuronic acid. The difference between these monosaccharides is that glucose contains the hydroxymethyl group at C5, while hexuronic acid has the carboxyl group at C5. Apart from this, the two monosaccharides are identical. Hence the observed difference in physicochemical properties of the above polysaccharides can be interpreted in terms of the structural difference at $\mathrm{C} 5$ of their units. Consequently, our results suggest that purines (exemplified by A) selectively bind to the carboxyl group of uronic acid residues, while pyrimidines interact with the hydroxymethyl group of hexose residues contained in polysaccharides. These experimental findings agree with the results of quantum chemical computations performed for the NApolysaccharide complexes, testifying again to their adequacy.

The bonding of nucleotides and glycans was detected in experiments aimed at studying the interaction between mature GAG (HA and CS) with fragmented calf thymus DNA. In primary structure, HA is a multiple tandem repeat of a unit consisting of a hexose and an uronic acid residue. In turn, tandem repeats of purine-pyrimidine account for a considerable proportion of DNA in higher organisms, including calf thymus DNA (Kiselev L.L. 2000, Singer M., et al. 1998). As our results demonstrate, HA did find complementary regions in calf thymus DNA. CS showed no complementary interactions with calf thymus DNA. It is known that C6 of hexose residues of CS is modified with the sulfo group, which provides an additional partial negative charge. This modification of hexoses dramatically affects the physicochemical properties of the polysaccharide and probably prevents hydrogen bonding.

Dot hybridization confirmed possible complementarity of hexoses to pyrimidines and uronic acid to purines. The specific bonds between NA and polysaccharides are comparable in strength with the bonds between complementary nucleotides in DNA. 
Thus, analysis of the interactions between polysaccharides and NA showed that purines of NA are complementary to uronic acids of polysaccharides and that pyrimidines are complementary to hexoses. The relationships between the genetic apparatus of the cell and polysaccharides deserve further studying in terms of the above complementarity principle. Such studies will probably yield a fundamentally novel view as to whether microheterogeneity of polysaccharide moieties of proteoglycans is genetically determined and related to purine-pyrimidine DNA repeats. Yet it is clear that the nature of these relationships need additional comprehensive studies.

The idea that polysaccharide moieties of proteoglycans contain information is not new. For instance, Zimina (Zimina N.P., et al. 1992, Zimina N.P., et al. 1987, Zimina N.P., et al. 1986, Zimina N.P., Rykova V.I., Dmitriev I.P. 1987) demonstrated that carbohydrate chains of proteoglycans are chemically heterogeneous and structurally irregular and concluded, quite justifiably, that the information content of proteoglycans provides a chemical basis for their intricate and highly specific functions in the cell. There is still no method for GAG sequencing, and data on the structure of their chains are circumstantial. Since chemical heterogeneity is widespread, these data make it possible to assume that proteoglycan chains are of irregular structure with a cluster arrangement of disaccharides. The clustering of bonds sensitive to testicular hyaluronidase and, consequently, of glucuronic acid residues was demonstrated for pig skin dermatan sulfate. The clusters are arranged along the chain without any distinct regularity (Fransson L.A., et al. 1982). Likewise, glucuronic acid-containing disaccharides are clustered at random along the chain of dermatan sulfates from the pig intestinal mucosa and the umbilical cord (Fransson L.A., et al. 1982). The clustering of various uronic acid residues is characteristic of dermatan suflate from the human uterine neck. The irregularity of dermatan sulfate chains was suggested from chromatographic elution profiles of dermatan sulfate isolated from the bovine aortic intima and digested with chondroitinase AC (Oegema T.R., et al. 1979). Structural studies revealed a cluster organization of HS and heparin chains. Their molecules include extended regions consisting of low-sulfated disaccharides that contain glucuronic acid residues as a main component and only a minor amount of glucose residues (Bjork I., et al. 1982). Clusters sulfated to a high extent were also found: they consist of highly charged disaccharides harboring glucose residues as a main component. These clusters are possibly separated by less ordered regions where alternating sugars occur in similar proportions. Molecules vary in size of highly and low-charged regions.

It should be noted that the structure of oligosaccharide sites is an informative element of GAG as opposed to NA, which contain information in the form of a strict sequence of monomeric units (nucleotides). For instance, the capability of self-association of proteoHS and proteodermatan sulfates is due to so-called contact zones, specific regions with alternating disaccharides containing glucuronic acid and glucose residues with a certain arrangement of sulfo groups (Franson L.-A. 1982). It is noteworthy that polysaccharides are characterized by a determined structural-functional interdependence similar to that of NA (Zimina N.P., et al. 1992).

The concept of nontemplate synthesis of polysaccharide components of proteoglycans does not allow a genetically grounded explanation of microheterogeneity (polymorphism) of 
proteoglycans. Yet data are continuously accumulating that polysaccharide components of proteoglycans are highly polymorphic and that their polymorphism shows distinct tissue, organ, and species specificities. It should be noted that glycans are still poorly understood and, consequently, the current views of glycans are similar to the views of NA in early molecular biology. Compounds belonging to one class strikingly differ in primary structure. We know today that, for instance, every mRNA is a unique element in realization of genetic information, but such functions are still to be elucidated in the case of glycans.

We characterized the fraction composition of polysaccharides contained in the rat liver homogenate. As Fig. 18 shows, rat liver polysaccharides include polymers of neutral sugars, hexoses, and hexuronic acids and vary in proportions of monomeric units and the degree of their modification (amination, sulfation, epimerization, etc.).

Correlation analysis revealed an association between time and synthesis of HS, which are GAG modified to the greatest extent. This result is beyond doubt because their modification is known to result in a high degree of sulfation and, consequently, their maturation takes more time as compared with maturation of other GAG groups.

In addition, the analysis results (Pearson empirical correlation coefficients and Spearman rank correlation coefficients) showed a strong linear correlation between cell nuclear structures (DNA) and the fraction of nuclear saccharides eluted from DEAE cellulose until $0.15 \mathrm{M} \mathrm{NaCl}$. Such a correlation was not observed for total DNA and the $0.15 \mathrm{M}$ fraction of the homogenate (oligosaccharides of microsomes, lysosomes, nuclei, other cell structures, and the intercellular matrix). The correlation testifies that nuclear synthesis of saccharides of this group increases after a glucose load, especially $1 \mathrm{~h}$ after loading. This finding was confirmed by quantitating polysaccharides with normalization with respect to the DNA content (Fig. 19).

The $0.15 \mathrm{M}$ fraction of the homogenate distinctly correlated with the contents of mature proteoglycans in the homogenate and the nucleus, implicating saccharides of this fraction in GAG maturation. In other words, an increase in synthesis of this saccharide fraction of the homogenate increased synthesis of proteoglycans (CS and HS). The fact that proteoglycan synthesis starts with this fraction was evident from the data on incorporation of radiolabeled glucose in GAG. It should be noted that the $0.15 \mathrm{M}$ fraction varies in composition among cell structures. The nuclear fraction harbors neutral sugar components and uronic acids at 3:0.75, suggesting incomplete addition of uronic acids to neutral trisaccharide units, which takes place in the nucleus. The $0.15 \mathrm{M}$ fraction of nuclear saccharides consists mostly (to $83 \%$ ) of components eluted at $0.02 \mathrm{M} \mathrm{NaCl}$. The 0.06 and $0.15 \mathrm{M}$ subfractions occur at 11 and $6 \%$, respectively. In microsomes, the proportion of the $0.02 \mathrm{M}$ subfraction is decreased to $55 \%$, while the proportions of the 0.06 and $0.15 \mathrm{M}$ subfractions are increased to 22 and $23 \%$, respectively. The changes observed in the homogenate are similar to those in microsomes, but the proportion of the $0.15 \mathrm{M}$ subfraction is greater (up to $32 \%$ ).

These findings associate the genetic apparatus of the cell with synthesis of oligosaccharides similar in composition to the universal tetrasaccharide of proteoglycans. The association is also evident from the results obtained with radiolabeled glucose: the label accumulation rate in nuclear structures was higher than in other structures $1 \mathrm{~h}$ after a glucose load. 
Oligosaccharides with a neutral sugar : uronic acid ratio of 3:1 are most probably synthesized in the nucleus. Heteroglycan chains with a tandem arrangement of uronic acidhexose units (1:1) are formed in structures of the microsomal fraction.

Analysis of incorporation of radiolabeled glucose in the nuclear and microsomal fractions of the cell (Fig. 23) showed that the incorporation rate is more intense in the nucleus early (at the end of the first hour) after a glucose load. After $2 \mathrm{~h}$, microsomes accumulate radiolabeled glucose to a high extent, which is probably due to a transfer of radiolabeled oligosaccharides from the nucleus and the formation of GAG chains. After $3 \mathrm{~h}$, the content of radiolabeled saccharides in the cell nucleus increased again owing most probably to a transfer of mature GAG from the EPR. This scenario agrees with modern views of proteoglycan synthesis.

It is of interest that the label appeared first in the $0.15 \mathrm{M}$ fraction and then in mature GAG (the $0.25-1.5 \mathrm{M}$ fraction) of the homogenate (Fig. 22). The initially high radioactivity of this fraction can be explained by the presence of glycans involved in initiating synthesis of the polysaccharide chain of GAG. GAG synthesis starts with xylosylation of core proteins and generation of a linker tetrasaccharide; then, the polysaccharide chain is formed by consecutive addition of hexoses and uronic acids in almost equal proportions.

Comparison of the data on radiolabeled glucose incorporation in GAG and fractions of cell structures showed that the high rate of label accumulation in the nucleus early (within the first hour) after a load was associated with the dynamics of label incorporation in polysaccharides eluted until $0.15 \mathrm{M} \mathrm{NaCl}$. This was not the case with mature GAG, which showed the highest radioactivity only $2 \mathrm{~h}$ after a load. At this time, the label content is minimal in the nucleus and higher in microsomes. Hence, we can state that generation of the GAG chain in the cell is associated with microsomes, while synthesis of the linker tetrasaccharide, which belongs to the $0.15 \mathrm{M}$ fraction, is associated with nuclear structures.

Saccharides of the $0.15 \mathrm{M}$ fraction differ from classical GAG in having another hexosamine content and probably harbor fragments with linker tetrasaccharides. Note that, until uronic acid-hexosamine ratio reaches 1:1 (as characteristic of HA), such fragments, having a considerable portion of neutral sugars, are eluted from the column at an ionic strength lower than necessary for $\mathrm{HA}$ elution $(0.15 \mathrm{M} \mathrm{NaCl})$. Since proteoglycan synthesis starts with generation of the linker tetrasaccharide, the radioactivity of this fraction should be higher early after a radiolabeled glucose load. Our results fully agreed with this expectation.

Thus, the glycoside moiety of proteoglycans is probably synthesized in a stepwise manner in the cell. The linker tetrasaccharides are synthesized in structures associated with the cell nucleus, which is also evident from the results of correlation analysis. Then the fragments are transferred into the EPR, where the main glycan chain is synthesized, biochemically modified, and used to form proteoglycans. The GAG chain is synthesized in the EPR. Mature GAG are delivered into the nucleus in a small amount and are mostly exported into the intercellular space to produce the intercellular matrix. This scenario agrees with data of many studies that core proteins entering the EPR and Golgi system already have the linker tetrasaccharide (xylose-galactose-galactose-uronic acid) (Colman Y., et al. 2000, Zimina N.P., et al. 1992, 
Zimina N.P., et al. 1987, Silbert J.E. et al. 1995). These data indirectly support our assumption that DNA plays a role in synthesis of the universal tetrasaccharide of proteoglycans.

Based on our data, we suggest a conceptual mechanism underlying the functional association between the nuclear apparatus and the formation of the tetrasaccharide linking the protein core with the GAG moiety in proteoglycans.

Taken together, the results obtained with different methods allow us to propose a concept of template synthesis of proteoglycans with the involvement of tandem DNA repeats.

It is clear that proteoglycan synthesis starts with DNA transcription to yield pre-mRNA. The informative region of the mRNA for the core protein is formed according to the commonly accepted mechanism up to the serine codon. When the serine codon is followed by a triplet complementary to the trisaccharide uronic acid-hexose-hexose, the mode of transcription changes. It should be noted that the complementarity requirements are met only by eight DNA triplets (ACC, ACT, ATC, ATT, GCC, GCT, GTC, and GTT). The energy of bonding during NA synthesis is distributed as follows among these triplets: it is about $11.7 \mathrm{kcal} / \mathrm{mol}$ in one triplet (GCC), $9.6 \mathrm{kcal} / \mathrm{mol}$ in three triplets (GCT, GTC, and ACC), $7.6 \mathrm{kcal} / \mathrm{mol}$ in three triplets (GTT, ACT, and ATC), and $5.5 \mathrm{kcal} / \mathrm{mol}$ in one triplet (ATT). Thus, the ATT triplet has the bonding energy of only $5.5 \mathrm{kcal} / \mathrm{mol}$ per monomer, lower than in the triplet duplex DNA-polysaccharide (more than $7 \mathrm{kcal} / \mathrm{mol}$ ).

Under certain conditions, this situation with the ATT codon may lead to appreciable competition with UDP-sugars in the formation of complementary pairs during RNA synthesis on DNA. As a result, synthesis of a trisaccharide may be more advantageous in terms of energy than addition of three structural units to RNA. Hence the following process is possible. Glycosyltransferase utilizes the first uronic acid residue bound to DNA adenine via complementary interactions and generates a bond between the saccaride and the last ribonucleotide of the serine codon of RNA, simultaneously converting uronic acid to xylose via decarboxylation at $C_{5}$. Decarboxylation initiates separation of the saccharide unit from DNA. Then, Gal transferases generate glycoside bonds between xylose and two hexose (galactose) residues, which are hydrogen-bonded to the thymine tandem of DNA according to the above scheme.

It is clear that some pre-mRNAs synthesized in vivo under such conditions have the trisaccharide xylose-galactose-galactose in place of a ribonucleotide triplet at the site of RNA branching on the ATT codon of DNA. It is well known that the ATT triplet determines a stop codon (UAA) terminating synthesis of polypeptide chains, which indirectly supports our assumption. If this sequence is followed by tandem repeats (purine-pyrimidine, such as CA) with a strength of bonding in NA synthesis about $8.8 \mathrm{kcal} / \mathrm{mol}$, synthesis of oligosaccharide is disadvantageous and the RNA is extended according to the DNA-RNA complementarity rule, which is more advantageous in terms of energy. Although the energy of bonds plays an important role in this situation, we assume that the process is still far more intricate.

Thus, it is possible that hnRNA contains pre-mRNAs that have a trisaccharide followed by a tandem ribonucleotide repeat consisting of more than 300 monomers (which is sufficient for 
generating the glycoside moiety of proteoglycans) and starting from 5'-P-terminal guanosine at the nuclear RNA branching site. This can explain why the corresponding RNA regions block reverse transcription and are resistant to some RNases. Guanine acts as a hnRNA branching site and, as a purine, is capable of ensuring further addition of the first uronic acid residue, which always follows the trisaccharide. With the above system of complementary interactions, the trisaccharide is analogous to UAA and, when immediately followed by GU, allows the processing and splicing of pre-mRNA according to the commonly accepted scheme. Like adenines, the two galactose residues may interact with two uridines of the spliceosome U-RNA through their hydroxymethyl groups. Thus, the sequence Gal-Gal-G-U provides a binding site for spliceosome structures, as characteristic of the splicing tetranucleotide consensus sequence (AAGU).

In such an RNA strand, saccharides are linked by the $3^{\prime}-5^{\prime}$ bond up to the end of the serine codon. $\mathrm{C}_{2}$ of the saccharide of the last nucleotide of the serine codon interacts with $\mathrm{C}_{5}$ of xylose, which is thereby capable of binding through $C_{1}$ with serine when xylosylation is initiated. Then xylose $\mathrm{C}_{4}$ binds with $\mathrm{C}_{1}$ of a galactose dimer. $\mathrm{C}_{2}$ of the last galactose interacts with $C_{5}$ of the saccharide moiety of guanosine. Thus, $C_{3}$ of the last nucleotide of the serine codon and $\mathrm{C}_{3}$ of the last galactose are free for bonding, which allows a 3-1 bond with the first glucuronic acid residue. Uridine following guanosine in an RNA intron determines the addition of a hexose to the glucuronic acid residue through the 4-1 (or 3-1) bond during template synthesis of a polysaccharide (Fig. 24).

Invariant GG at the 5' end of the next exon, continuing the protein-coding sequence, represents the first two nucleotides of a glycine codon (GGA, GGG, GGC, or GGU). This GG is in the trisaccharide site (the RNA branching site) and, as the flanking intron is excised in the processingosome during RNA maturation, continues the mRNA coding region after the serine codon in the $5^{\prime}-3^{\prime}$ direction. The obligatory presence of invariant splicing-site GG in the triplet following the serine codon can explain the conservation of the xylosylation site (serine-glycine tandem) among core proteins, because only glycine codons start with two guanines.

The resulting transcript is capable of directing synthesis of a polypeptide chain wherein serine is covalently bound to the trisaccharide and then with glycine. Tandem RNA sequences, representing the intron side chain following the tetrasaccharide (xylosegalactose-galactose-uronic acid), allow a polysaccharide fragment to be synthesized according to the NA base-monosaccharide complementarity by glycosyltransferases that form 4-1 or 3-1 glycoside bonds, starting from the last saccharide. After splicing occurs and the two guanines find themselves in the exon part of the molecule, the tandem RNA fragment is linked to $\mathrm{C}_{2}$ of uronic acid through the terminal uridine. The fragment determines an ordered arrangement of monosaccharides for synthesis of a polysaccharide chain. This process is advantageous (bonding energy is about $7 \mathrm{kcal} / \mathrm{mol}$ ) in systems having an excess of UDP-saccharides and glycosyltransferases and lacking mononucleotides and NA polymerases, as characteristic of membrane structures of EPR and the Golgi complex. We propose that the process is termed glycotranscription, because information contained in NA is directly transferred to the polysaccharide chain. 


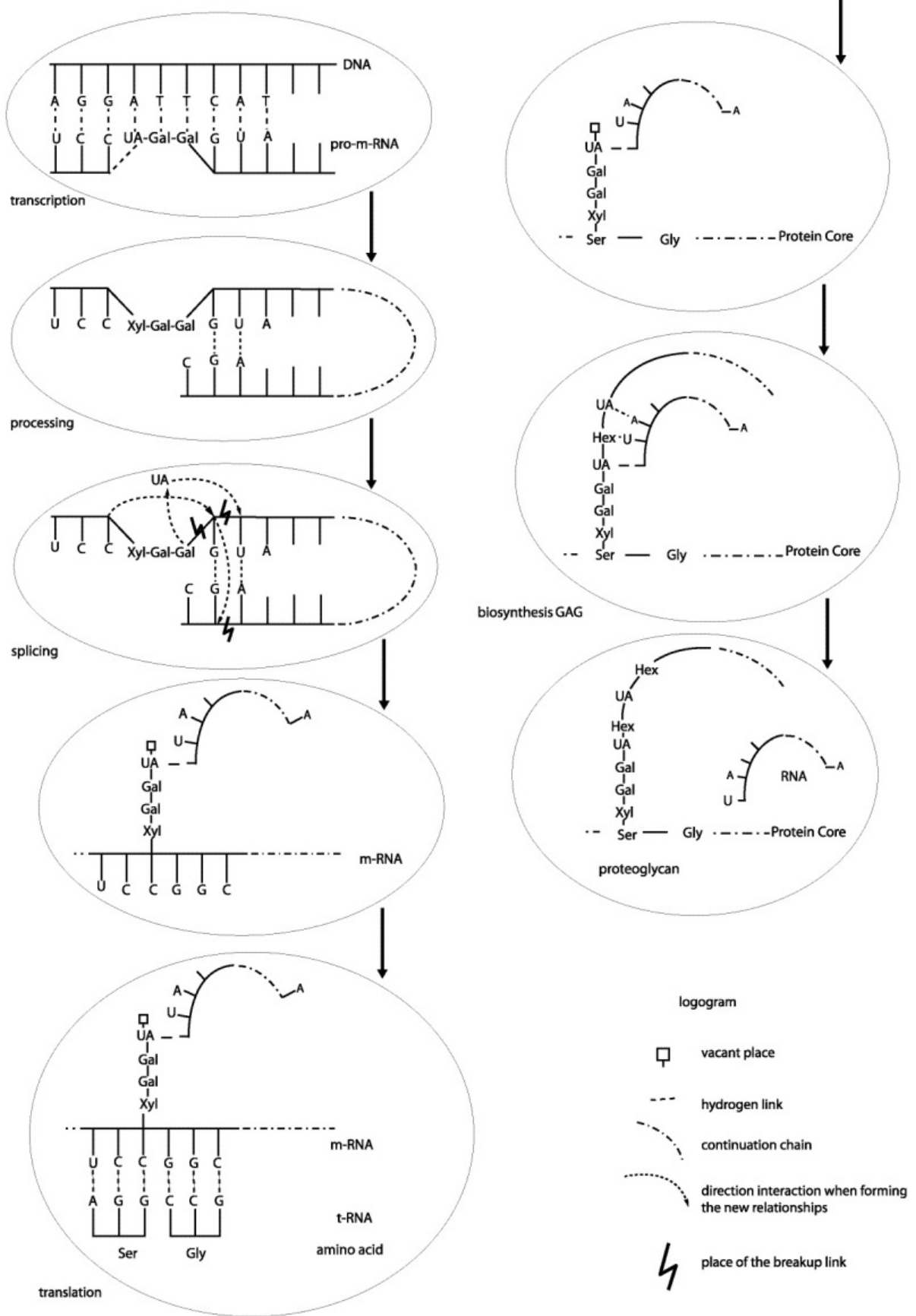

Figure 24. Hypothetical scheme of genetically determined template synthesis of proteoglycans. 
It is clear that synthesis of the core protein chain on ribosomes is quite possible, because the tetrasaccharide does not occupy the $3^{\prime}-5^{\prime}$ bond of the last nucleotide of the serine codon and acts as a spacer linking the RNA intron. As a result, the newly synthesized core protein contains the linker tetrasaccharide and the RNA intron attached to the serine. The protein is delivered after synthesis into the site where the corresponding polysaccharide fragment is generated in membrane structures of the EPR and the Golgi complex. Serine is xylosylated in the EPR during biosynthesis of the core protein on ribosomes. This scenario does not contradict the modern views of GAG synthesis (Silbert J.E. et al. 1995).

It should be noted that pre-mRNA splicing is tissue-specific. Moreover, selection of the splicing site depends on the developmental stage in some cases (Singer M., et al. 1998). In other words, the primary structure of mRNA introns varies with tissue and ontogenetic stage. The same is true for the primary structure of the glycoside moiety of proteoglycans. It is known that proteoglycans are completely absent from unicellular and prokaryotic organisms, as well as pre-mRNA processing is. This fact suggests a relationship between glycan biosynthesis and mRNA maturation in terms of biological significance for the cell.

This assumption is supported by data obtained for mRNAs of CS core proteins. Translated in a cell-free wheat germ system, cartilage mRNA directed synthesis of a 340-kDa core protein. Immediately after translation, the protein already contained glycosylation signals for subsequent glycan synthesis (Hook M., et al. 1984), i.e., the linker tetrasaccharide was already present.

Based on quantum chemical analysis of the advantage of bonding, the hypothesis of proteoglycan synthesis of the NA template (Fig. 24) agrees with the views of the processes involved in realizing genetic information (genome structure, transcription, hnRNA processing and splicing, translation) (Singer M., Berg P. 1998) and eliminates the main contradictions of the existing concept of proteoglycan metabolism. The hypothesis explains why the site where the linker tetrasaccharide is attached to the protein core has not been identified in more than fifty years of studies on proteoglycans: the tetrasaccharide is already contained in RNA before translation. There is convincing evidence that the tetrasaccharide finds its way in the EPR as covalently bound to the core protein (Colman Y., et al. 2000, Silbert J.E. et al. 1995). A role of protein core structures in determining the serine xylosylation site was rejected in recent studies. A "vitalistic" hypothesis has been formulated that ascribes this role to intracellular membranes. The hypothesis is based on the fact that glycosyltransferases are mostly in membrane structures of the EPR and Golgi complex (Silbert J.E. et al. 1995). Yet this fact alone does not prove synthesis of the linker tetrasaccharide in these structures, because glycosyltransferases are also detectable in nuclei (nuclear membranes). Our biochemical studies implicate structures of the cell nucleus in initiation of synthesis of the linker tetrasaccharide.

According to our hypothesis, a serine is subject to xylosylation only when its codon is followed in DNA consequently by the ATT stop codon and CA (GU in RNA) of an intron, responsible for hnRNA branching and mRNA processing. 
The above scheme of proteoglycan synthesis allows generation of a linear heteroglycan of a particular size (about 300 monomers). The question is how template synthesis following this scheme proceeds in the case of HA, consisting of thousands of monomers. It is clear that RNA templates of a corresponding size are absent from EPR structures. It is possible that GAG synthesis in this case utilizes lasso-like intron RNA, which result from cis-splicing and are potentially capable of directing cyclic synthesis of HA with any number of monomeric units. It is known that mRNA trans-splicing yields linear introns. Such RNA structures may direct template synthesis of branched homoglycans whose branching period is a multiple of the full NA helix turn (10-12 units). Monosaccharide 10 (12) overlies monosaccharide 1 of the nascent strand under these conditions, which allows an additional bond between them. Then synthesis proceeds through several such rounds to yield a branched polysaccharide structurally similar to glycogen. This hypothetical mechanism generating branched polysaccharides is supported by the fact that their branching period is a multiple of the full NA helix turn.

RNAs with the above structures may be components of small cytoplasmic RNA, the role of which is still poorly understood. It is known that scRNA account for less than $1 \%$ of total cell RNA. Some scRNAs contain tandem repeats, in particular, Alu sequences. These scRNAs are associated with membrane structures of the EPR. Some scRNAs (7SL RNA) are involved in transmembrane transport of polypeptides across the EPR lipid bilayer. The scRNA size varies from 90 to $330 \mathrm{nt}$, which falls well into our concept. It should be noted that synthesis of storage homoglycans probably requires no template and proceeds through a simpler mechanism, because their chains carry no information.

Many glycoproteins act as antigens on the plasma membrane. Immunohistochemical comparison of glycoproteins isolated from hepatocyte membranes of intact, embryonic, and regenerating liver and from hepatoma showed that the protein component of antigens is detectable on all hepatocytes regardless of the state of the liver. Moreover, the protein component is tissue-nonspecific and universal for most cell groups. The carbohydrate component of antigens proved to be specific. It is the structure of the polysaccharide component that determines the immunogenicity of a proteoglycan. Zimina (Zimina N.P., et al. 1987) studied the specifics of GAG synthesis in the liver of adult rats and embryos and in hepatoma and showed that GAG of tissues with active cell proliferation are sulfated to a lower extent as compared with the corresponding GAG of quiescent tissues. That is, polysaccharide fragments of the same proteoglycans differ depending on the state of hepatocytes.

According to the concept of nontemplate synthesis of GAG, the protein core is synthesized on polysomes of the rough EPR. The same protein components of proteoglycans were synthesized in all above cases. The identity of the protein core suggests that the glycoside components of these proteoglycans are synthesized in one site of the smooth EPR and, consequently, are also identical. Experimental results contradict this assumption. The variation of glycoside components is possible only when glycosyltransferase complexes of EPR membranes vary depending on the physiological state of hepatocytes. A glycosyltransferase complex of the smooth EPR should contain about 300 molecules of the enzyme generating the glycoside bond in a certain sequence. For instance, HS synthesis 
requires a complex of about 300 N-acetylglucosaminylatransferases and glucuronyltransferases occurring in equal proportions. Each of the 150 enzyme molecules, e.g., N-acetylglucosaminyltransferases, should be encoded by a separate gene with a nonconserved sequence coding for the site of enzyme attachment to a strongly specific membrane site of the smooth EPR. If GAG synthesis is template-independent, at least three types of such complexes are necessary for HS generation. About $450 \mathrm{~N}$ acetylglucosaminyltransferase genes are required for this process. Since the enzyme is also involved in synthesis of heparin and other polysaccharides, the number of $\mathrm{N}$ acetylglucosaminyltransferase genes should occur at thousands of copies per genome. Yet it is known that DNA regions complementary to mRNAs have unique sequences and occur at a few copies per genome. Glycosyltransferase genes are not exceptions to this rule. Thus, the commonly accepted hypothesis of nontemplate synthesis of GAG cannot explain the genetically determined heterogeneity of polysaccharide components of proteoglycans. This hypothesis does not stand up, since recent works have demonstrated the informative value of the glycoside moiety of proteoglycans (Zimina N.P., et al. 1992, Zimina N.P., et al. 1987).

Our scheme of template synthesis of GAG solves this problem, because only a few glycosyltransferase genes are sufficient for generating any diversity of polysaccharide chains in this case.

Synthesis of some glycans with a high information content according to the glycotranscription principle makes it possible to assume, by analogy with RNA, the existence of reverse glycotranscription, whereby information is transferred from polysaccharide to RNA and then, by reverse transcriptase, to DNA fragments, which can be inserted into the genome to preserve the acquired information about new glycans in the genome structure. Such information is contained in specific tandem DNA repeats, which are unique for each individual. The relevant genetic systems are probably capable of being transmitted to the progeny and being fixed as a hereditary or acquired character by selection. It seems that both nontemplate and genetically determined template synthesis of polysaccharides exist in nature and are closely associated with each other through information flows.

It should be noted in this connection that Ronichevskaya and Rykov (Ronichevskaya G.M., Rykova V.I. 1977) observed that GAG suppress DNA replication in proliferating cells in a keilon-like manner. This observation can be explained by homology of polysaccharides to NA. We think that polysaccharide fragments are capable of blocking DNA polymerases via specific binding to complementary DNA repeats. As reported earlier, the substances examined in (Ronichevskaya G.M., et al. 1977) were isolated from RNA preparations, which provides indirect evidence for a role of RNA in glycan synthesis. According to our results, HA fragments form stable bonds with NA.

Further studies of proteoglycan polymorphism (species and tissues specificity, age- and pathological changes) and development of sequencing technique will probably demonstrate the specificity of proteoglycans at the level of individual organisms. By analogy, polymorphism of highly repetitive genome sequences is now beyond doubt and is widely used in genome fingerprinting. We assume that it is genomic repeats that are responsible for 
the information structure of glycans, whose polymorphism (microheterogeneity) has come to be commonly recognized.

The results of many studies implicate proteoglycans in intricate processes regulating cell proliferation (Ronichevskaya G.M., et al. 1977) and differentiation (Kinoshita S., et al. 1979, Kinoshita S., Yoshii K. 1979), cell recognition, and the organization of intercellular interactions (Henkart P., et al. 1973). In evolution, polysaccharides played a key role in the transition from unicellular organisms to multicellular entities. It is owing to polysaccharides that the individual cell functions as a structure with a particular function in the cell ensemble of the total organism. In the ontogeny, proteoglycans are associated with the aging of cells, tissues, and organs (Zimnitskii A.N., et al. 2004). A genetic defect in synthesis of GAG polysaccharide chains leads to severe hereditary disorders (Zimnitskii A.N., Bashkatov S.A. 2004 ). It is beyond doubt that the relevant processes are controlled by DNA, which carries genetic information.

To conclude, life is a mode of existence of not only protein and nucleic, but also of polysaccharide bodies, because all three biopolymers determine life that we observe. Analysis of the distinct association of NA and polysaccharides will clarify the role of both polysaccharides and DNA repeats. The latter cannot be described now as waste or selfish, because some of them are potentially capable of directing polysaccharide synthesis.

We are grateful to prof. N.K. Yankovskii (Institute of General Genetics, Russian Academy of Sciences, Moscow) and Dr. V.I. Salyanov (Institute of Molecular Biology, Russian Academy of Sciences, Moscow) for help in collecting and interpreting empirical data.

\section{Author details}

Aleksandr N. Zimnitskii

«NanoDerm-profi» Ltd., Moscow, Russia

\section{References}

Altschuler C.H., Kinsman G., Bareta J.(1963). Connective tissue metabolism: I. Hyaluronic acid synthesis by cell-free extracts of human tissues. Arch Pathol. Feb;75:206-211.

Belozersky A.N. (1970). Methods for Studying Nucleic Acids. Moscow: Mir.

Blagoi Yu.P., Galkin V.L., Gladchenko G.O., Kornilova S.V. (1999). Metallocomplexes of Nucleic Acids in Solutions. Kiev: Naukova Dumka, 199p.

Bjork I., Lindahl. U. (1982). Mechanism of the anticoagulant action of heparin. Mol Cell Biochem.18:161-82..

Chaplin M.F., Kennedy J.F.(1986). Carbohydrate Analysis: A Practical Approach. Oxford, Washington.

Cifonelli J.A., Dorfman A.J.(1957). The biosynthesis of hyaluronic acid by group A streptococcus: V. The uridine nucleotides of group A streptococcus. J Biol Chem. Oct; 228(2):547-57.

Colman Y., Rem C.-G. (2000). Illustrative Biochemistry. Moscow: Mir. 
Cybulski S.M., Scheiner S.J.(1989). Hydrogen bonding and proton transfers involving the carboxylate group. J Am Chem Soc., 111, p.23-31.

Denhardt D.T.(1966). A membrane-filter technique for detection of complementary DNA. Biochem Biophys Res Commun., 23:641-52.

Dewar M.J.S., Zoebisch E.G., Healy E.F., Stewart J.J.P. (1985). Development and use of quantum mechanical molecular models. 76. AM1: A new general purpose quantum mechanical molecular model. J Am Chem Soc.,107, p.3902-3909.

Dorfman A. (1958). Studies on the biochemistry of connective tissue. Pediatrics. Sep;22(3):576-89.

Dorfman A. (1964). Metabolism of acid mucopolysaccharides. Biophys J. Jan; 71:SUPPL 15565.

Dorfman A.(1965). In: Structure and Function of Connective and Skeletal Tissue. London,178, 297.

Dunin V.V., Rukhadze E.G., Potapov V.M.(1979). Generation and Analysis of Optically Active Compounds. Moscow: Mosk. Gos. Univ.

Fransson L.A., Havsmark B. (1982). Structural requirements for heparan sulphate selfassociation. Carbohydr Res., 16:135-44.

Franson L.-A.(1982). Structural features of the contact zones for heparan sulphate selfassociation. Carbohydr Res.,110:127-33.

Glaser L., Brown D.H.(1955). Purification and properties of d-glucose-6-phosphate dehydrogenase. Proc. Natl. Acad. Sci. USA, 41:253.

Henkart P., Humphreys S., Humphreys T.(1973). Characterization of sponge aggregation factor: A unique proteoglycan complex. Biochemistry., 12:3045-50.

Hook M., Kjellen L., Jahansson S., Robinson J.(1984). Cell-surface glycosaminoglycans. Annu Rev Biochem., 53:847-69.

Jeffrey D Esko, Zhang L.(1996). Influence of core protein sequence on glycosaminoglycan assembly Curr Opin Struct Biol. 5:663-70.

Jermyn M.A.(1975). Increasing the sensitivity of the anthrone method for carbohydrate. Anal Biochem., 68:332-5

Jurema J.M.W., Shields G.C.(1993). Ability of the PM3 quantum-mechanical method to model intermolecular hydrogen bonding between neutral molecules. J Comput Chem. 14 , p.89-104.

Kallies B., Mitzner R. (1995). The ability of the semiempirical PM3 method to model proton transfer reactions in symmetric hydrogen bonded systems. J Mol. Model., 1, p.68-78.

Kinoshita S., Yoshii K.(1979). The role of proteoglycan synthesis in the development of sea urchins: II. The effect of administration of exogenous proteoglycan. Exp Cell Res.,123:361-9.

Kinoshita S., Saiga H. (1979). The role of proteoglycan in the development of sea urchins: I. Abnormal development of sea urchin embryos caused by the disturbance of proteoglycan synthesis. Exp Cell Res., 123:229-36.

Kiselev L.L. (2000). Human genome and biology of the 21st century. Vestn Ross Akad Nauk., 70: 414-24.

Latajka Z. Scheiner S.J. (1990). Structure, energetics, and vibrational spectrum of ammonia...water. J Phys Chem. 94, p.217-221. 
Lindahl U., Kjellen L.(1987). Biology of Proteoglican. Wight T.N., Mecham R.P., Eds., Orlando: Acad. Press. p. 59.

Lorenzel I.(1959). Epinephrine-induced alterations in connective tissue of aortic wall in rabbits. Proc Soc Exp Biol Med. Nov;102:440-2.

Maley F., Maley G.F. (1959).The enzymic conversion of glucosamine to galactosamine. Biochim Biophys Acta. Feb;31(2):577-8.

Markovic O., Huttl S.(1964). Contribution to a methodical approach to determination of protein and glycoprotein components in synovial fluid. Cas Lek Cesk. May 8;103:522-5. Czech.

Markovitz A., Cifonelli J.A., Dorfman A. (1958). Biosynthesis of hyaluronic acid by cell-free extracts of group-A streptococci. Biochim Biophys Acta. May;28(2):453-5.

Maxam A., Gilbert W.(1977). A new method for sequencing DNA. Proc Natl Acad Sci USA. 74:560-4.

Mednikov B.M., Shubina E.A., Mel'nikova M.N. (2001). Molecular mechanisms of genetic isolation. Priroda, 5: 19-28.

Mulliken R.S.(1955). Electron population analysis on LCAO-MO molecular wave functions: II. Overlap populations, bond orders, and covalent bond energies. J Chem Phys. 23:18416.

Oegema T.R., Jr, Hascall V.C., Eisenstein R.(1979). Characterization of bovine aorta proteoglycan extracted with guanidine hydrochloride in the presence of protease inhibitors. J Biol Chem. 254:1312-8.

Orekhovich V.N., (1968). Ed Modern Methods in Biochemistry., Moscow: Meditsina.

Roberts J., Kaserio M.(1978). Basics of Organic Chemistry. Moscow: Mir.

Roden L., Dorfman A. (1958). The metabolism of mucopolysaccharides in mammalian tissues: V. The origin of L-iduronic acid. J Biol Chem. Nov;233(5):1030-3.

Rondle C.J.M., Morgan W.T. (1955). The determination of glucosamine and galactosamine. Biochem J. Dec;61(4):586-9.

Ronichevskaya G.M., Rykova V.I. (1977). Organic specificity of the antimitotic effect of glycopeptides isolated from RNA preparations. Dokl. Akad. Nauk SSSR., 237:481-3.

Roseman S., Ludowieg J., Moses F., Dorfman A.(1953). The biosynthesis of the glucuronic acid moiety of hyaluronic acid. Arch Biochem Biophys. Feb; 42(2): 472-3.

Roseman S., Moses F.E., Ludowieg J., Dorfman A. (1953).The biosynthesis of hyaluronic acid by group A streptococcus: I. Utilization of 1-C14-glucose. J Biol Chem. Jul; 203(1):213-25.

Roseman S., Moses F.E, Ludowieg J, Dorfman A.(1954). The biosynthesis of hyaluronic acid by group A streptococcus: II. Origin of the glucuronic acid. J Biol Chem.Feb; 206(2):665-9.

Schiller S.(1964). Synthesis of hyaluronic acid by a soluble enzyme system from mammalian tissue. Biochem Biophys Res Commun. Mar 26;15(3):250-255.

Schiler S.(1965). Structure and Function of Connective and Skeletal Tissue. London, p.302.

Strominger J.L.(1964). Nucleotide intermediates in the biosynthesis of heteropolimeric polysaccharides. Biophys J. Jan;71:SUPPL139-53.

Schmidt M.W., Baldridge K.K., Boatz J.A., Elbert S.T., Gordon M.S., Jensen J.H., Koseki S., Matsunaga N., Nguyen K.A., Su S.J., Windus T.L., .Dupuis M., Montgomery J.A.(1993). General atomic and molecular electronic structure system. J Comput Chem. 14, p. 13471363. 
Silbert J.J. (1963). Incorporation of 14C and 3H from nucleotide sugars into a polysaccharide in the presence of a cell-free preparation from mouse mast cell tumors. J Biol Chem. Nov;238:3542-6.

Silbert J.E. Sugumaran G .(1995). Intracellular membranes in synthesis, transport, and metabolism of proteoglycans. Biochim Biophys Acta. 1241(3):371-84.

35. Silbert J.E. (1982). Structure and metabolism of proteoglycans and glycosaminoglycans. J Invest Dermatol. 79(1):31-7.

Singer M., Berg P. (1998). Genes \& Genomes. A changing perspective. University science Books, Mill Valley, California.

Slutskii L.I.(1969). Biochemistry of Normal and Pathologically Changed Connective Tissue. Leningrad: Meditsina.

Strominger J.L.(1964). Nucleotide intermediates in the biosynthesis of heteropolimeric polysaccharides. Biophys J. Jan;71:SUPPL139-53.

Stewart J.J.P.(1989). Optimization of parameters for semiempirical methods: II. Applications. J Comput Chem. 10, p.221-261.

Sugahara K., Kitagawa H.(2000). Recent advances in the study of the biosynthesis and functions of sulfated glycosaminoglycans. Curr Opin Struct Biol. 10(5):518-27.

White J, Handler P., Smith E.L., Hill R.L., Lehman I.R., (1978). Principles of Biochemistry, 6th ed. , New York: McGraw-Hill, p.215.

Williams I.H.(1987). Theoretical modeling of specific solvation effects upon carbonyl addition. J Am Chem Soc. 109, p.6299-6307.

White B.N., Shetlar M.R., Shurley H.M., Shilling J.A. (1965). Incorporation of (114C)Glucosamine into mucopolysaccarides of rat connective tissue. Biochim Biophys Acta. Mar 1;101:97-105.

Yang J.T., Samejima T.(1969). Optical rotatory dipersion and circular dichroism of nucleic acids. In Progress in Nucleic Acids Research and Molecular Biology, Lavidson J.N., Cohn W.E., Eds., New York: Academic, pp.223-38.

Zelenin A.V.(2003). Plant genome. Vestn Ross Akad Nauk. 73:797-806.

Zimina N.P., Rykova V.I.(1986). Proteoglycans of animal tissues and their effect on DNA synthesis. Biokhimiya. 51:1555-61.

Zimina N.P., Dmitriev I.P., Rykova V.I.(1987). Composition and sulfation degree of glycosaminoglycans from tissues of various animals: Heterogeneity and tissue specificity of heparan sulfates. Biokhimiya. 52(6):984-90.

Zimina N.P., Rykova V.I., Dmitriev I.P.(1987). Comparison of composition and sulfation extent for glycosaminoglycans of quiescent and actively proliferating tissues. Biokhimiya, 52:856-61.

Zimina N.P., Rykova V.I., Arkhipov I.A. (1992). Animal tissue proteoglycans as irregular biopolymers: Informativeness of structure and control of biosynthesis. Usp Sovrem Biol. 112(4):571-88.

Zimnitskii A.N., Bashkatov S.A., Petrenko E.G., Khusnutdinova S.B.(2004). Age-related changes in skin glycosaminoglycan content in women, Biomed Khim., 50:309-13.

Zimnitskii A.N., Bashkatov S.A.(2004). Glycosaminoglycans in biochemical mechanisms of adaptation to some physiological and pathological states. Moscow, Globus: Farmatsevticheskii Byulleten. 